\title{
Indexierung des Rundfunkbeitrags und Stabilität der deutschen Rundfunkfinanzierung. Ansätze einer europarechtlichen Risikoanalyse
}

\author{
Dr. Jörg Ukrow, LL.M.Eur. *
}

I. Einleitung

II. Der unionsrechtliche Rahmen der Beurteilung der Rechtskonformität einer Vollindexierung der Fortschreibung des Rundfunkbeitrags .... 284

III. Zur Bedeutung der primärrechtlichen Wettbewerbsordnung der EU 286

1. Zur Einordnung des Rundfunkbeitrags als Beihilfe i.S. des Unionsrechts

281

2. Zur Bedeutung der Sonderregeln für Dienstleistungen von allgemeinem wirtschaftlichem Interesse

a) Einführung .............. 289

b) Die Altmark-Trans-Judikatur des EuGH 293

IV. Zur Bedeutung der kulturpolitischen Querschnittsklausel 296

V. Zur Bedeutung des Amsterdamer Protokolls über den öffentlich-rechtlichen Rundfunk 301

VI. Zur Bedeutung der Mitteilung der Kommission über die Anwendung der Vorschriften über staatliche Beihilfen auf den öffentlich-rechtlichen Rundfunk 302

1. Einführung 302
2. Die Kriterien der Mitteilung, die Überlegungen zur Fortentwicklung des Auftrages und der Übergang zu einer Vollindexierung der Finanzierung ....................... 303

a) Definition des öffentlichrechtlichen Auftrags .... 304

b) Betrauung und Kontrolle ...................... 307

c) Wahl des Systems zur Finanzierung des öffentlich-rechtlichen Rundfunks .................... 309

d) Transparenzanforderungen bei der Prüfung der staatlichen Beihilfe ....... 310

e) Nettokostenprinzip und Überkompensierung ..... 310

f) Finanzaufsichtsmechanismen .....

VII. Der Beihilfekompromiss aus

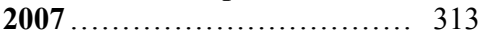

1. Einleitung .................. 313

2. Beihilfecharakter............ 314

3. Bestehende Beihilfe ......... 314

4. Vereinbarkeit der Finanzierungsregelung mit dem Gemeinsamen Markt ........ 316

a) Definition .................. 316

b) Beauftragung und Kontrolle ....................... 318

c) Verhältnismäßigkeit...... 319

* Der Verf. ist stv. Direktor der Landesmedienanstalt Saarland (LMS) und geschäftsführendes Vorstandsmitglied des Instituts für Europäisches Medienrecht (EMR). Kontakt: ukrow@lmsaar.de. Der Beitrag gibt ausschließlich persönliche Auffassungen des Verfassers wieder. 
VIII. Zur Bedeutung der jüngeren Judikatur des EuGH

1. Zum Verhältnis von Art. 107 Abs. 1, Art. 106 AEUV und Amsterdamer Protokoll ..... 321

2. Zur Unionsrechtskonformität des deutschen Rundfunkbeitragssystems der Finanzierung des öffentlich-rechtlichen Rundfunks 321

\begin{abstract}
Ein Übergang zu einem umfassend indexgestützten Modell der Finanzierung des öffentlichrechtlichen Rundfunks, der in verschiedenen Ausformungen auch unter dem Oberbegriff „Vollindexierung“ diskutiert wird, steht trotz hieran geäußerter rechtlicher und politischer Kritik weiterhin auf der medienpolitischen Tagesordnung. Die Reserven gegenüber einem solchen Ansatz, der je nach Ausformung mit einer ,Entpolitisierung “ und/oder einer Rücknahme bisheriger Kontrollmöglichkeiten der KEF verbunden wäre, sind im Länderkreis allerdings auch noch nicht abschließend ausgeräumt. Der Schwebezustand in Bezug auf die zukünftige Ausgestaltung der Finanzverfassung des öffentlich-rechtlichen Rundfunks dauert damit an.

Die Zurückhaltung gegenüber einem Wechsel zu einer umfassenden Indexierung des Rundfunkbeitrags wird im bisherigen medienpolitischen und -rechtlichen Diskurs im Wesentlichen verfassungsrechtlich begründet. Der Beitrag ${ }^{1 *}$ beleuchtet das juristische Risikopotential einer solchen „Vollindexierung “ unter unionsrechtlichem Blickwinkel. Dabei geht es nicht um eine abschließende Klärung, sondern um eine Beschreibung von Gefährdungslagen, mit denen sich die deutschen Länder - als die für eine auch unionsrechtskonforme positive Ordnung des Rundfunks Verantwortlichen - bei einer Fortentwicklung der Finanzierung des öffentlich-rechtlichen Rundfunks befassen müssen.

Der Beitrag beleuchtet hierzu zunächst das Zusammenspiel zwischen der Wettbewerbsordnung der EU und ihrer Gewährleistung kultur- und medienpolitischer Souveränitätsrechte der Mitgliedstaaten sowie der Anerkennung der besonderen demokratischen und gesellschaftlichen Rolle des öffentlich-rechtlichen Rundfunks in den Bestimmungen zur Daseinsvorsorge, der Querschnittsklausel des Art. 167 Abs. 4 AEUV und dem sog. Amsterdamer Protokoll zum öffentlich-rechtlichen Rundfunk. Er stellt sodann die Konkretisierung dieses Zusammenspiels in der allgemein geltenden Rundfunkmitteilung der Europäischen Kommission aus 2009 und dem auf die deutsche Rundfunkordnung bezogenen sog. Beihilfekompromiss aus 2007 dar und analysiert Orientierungspunkte, die diesen Sekundärrechtsakten
\end{abstract}

1 Der Beitrag knüpft an ein Aktuelles Stichwort des EMR „Indexierung auf dem Index des Unionsrechts?" (https://emr-sb.de/wp-content/uploads/2019/04/EMR-Aktuelles-Stichwort-Indexierung.pd f) an. 
mit Blick auf eine unionsrechtskonforme Ausgestaltung einer ,Vollindexierung “ entnommen werden können. Abschließend wird auch die bisherige Judikatur der Gerichte der EU auf Ansatzpunkte für eine solche Ausgestaltung hin untersucht.

Mangels gefestigter europarechtlicher Praxis verdichtet sich keines der Risiken zu einem apriorischen „No go “ für den Umstieg zu einem System einer umfassenden Indexierung der Entwicklung der Beitragshöhe. Es bleibt politischer Entscheidung i.S. einer medienrechtspolitischen und finanzverfassungsrechtlichen Entwicklungsprognose überlassen, ob der behauptete Nutzen einer solchen ,Vollindexierung“ als höher eingestuft wird, als die (nicht nur europa-) rechtlichen Risiken. Der Beitrag zeigt im Ergebnis Leitplanken auf, wie die unionsrechtlichen Risiken bei einem Übergang zu einer umfassenden Indexierung im System der Beitragsfinanzierung minimiert werden können und weist auch auf rechtspolitische Handlungsoptionen hin, die sich nicht zuletzt im Zuge der Neukonstituierung von EU-Organen im Nachgang zu den Wahlen zum Europäischen Parlament im Mai diesen Jahres eröffnen.

\section{Einleitung}

Die Ministerpräsidentenkonferenz hat sich in ihrer Sitzung am 21. März 2019 erneut mit Auftrag und Finanzierung des öffentlich-rechtlichen Rundfunks befasst und dabei folgenden Beschluss gefasst:

- „Es soll eine Profilschärfung des Auftrags vorgenommen werden. Danach soll in allen Bereichen künftig das öffentlich-rechtliche Profil der Angebote, das nicht marktwirtschaftlichen Anreizen folgt, sondern zu einer inhaltlichen Vielfalt beiträgt, die allein über den freien Markt nicht gewährleistet werden kann, als Gegengewicht zu den Angeboten der privaten Rundfunkanbieter stärker zum Ausdruck kommen. Die Beauftragung öffentlich-rechtlicher Angebote soll unter Beachtung der Erfordernisse des EU-Beihilfekompromisses flexibilisiert werden.

- Die Anstalten sollen gebeten werden, eine gemeinsame Plattformstrategie zu entwickeln.

- Als Ausdruck einer stärkeren Eigenverantwortlichkeit soll die Zuweisung eines Budgets eine weitergehende gegenseitige Deckungsfähigkeit von Aufwandspositionen und eine periodenübergreifende, konkret zweckgebundene Rücklagenbildung ermöglichen.

- Es soll geprüft werden, ob ab dem 1. Januar 2023 der Rundfunkbeitrag mittels eines Index angepasst werden soll. Der Grundwert der indexbasierten Anpassung könnte sich an dem zuvor auf der Basis des von der KEF für die Beitragsperiode ab 2021 ermittelten Finanzbedarfs der öffentlich-rechtlichen Rundfunkanstalten unter Berücksichtigung weiterer, von den Anstalten vorgeschlagener und von der KEF geprüfter Einsparungen durch die Besonderheiten der Systemumstellung orientieren. 
- Auch im Rahmen eines reformierten Finanzierungssystems müssen die besonderen Belange der kleineren und mittleren Anstalten berücksichtigt werden“". ${ }^{2}$

Damit steht ein Übergang zu einem umfassend indexgestützten Modell der Finanzierung des öffentlich-rechtlichen Rundfunks, der in verschiedenen Ausformungen auch unter dem Oberbegriff „Vollindexierung“ diskutiert wird, trotz hieran geäußerter rechtlicher ${ }^{3}$ und politischer Kritik ${ }^{4}$ weiterhin auf der medienpolitischen Tagesordnung. Die Reserven gegenüber einem solchen Ansatz, der je nach Ausformung mit einer „Entpolitisierung“ und/oder einer Rücknahme bisheriger Kontrollmöglichkeiten der KEF verbunden wäre, sind im Länderkreis allerdings, wie der erteilte Prüfauftrag belegt, auch noch nicht abschließend ausgeräumt. Der Schwebezustand in Bezug auf die zukünftige Ausgestaltung der Finanzverfassung des öffentlich-rechtlichen Rundfunks dauert damit an.

Die Zurückhaltung gegenüber einem Wechsel zu einer umfassenden Indexierung des Rundfunkbeitrags wird im bisherigen medienpolitischen und -rechtlichen Diskurs im Wesentlichen verfassungsrechtlich begründet. Die folgenden Ausführungen sollen einen weiteren Beitrag ${ }^{5}$ dazu leisten, das juristische Risikopotential einer solchen „Vollindexierung“ unter unionsrechtlichem Blickwinkel zu beleuchten. ${ }^{6}$ Dabei geht es nicht um eine abschließende Klärung, sondern um eine Beschreibung von Gefährdungslagen, mit denen sich die deutschen Länder - als die für eine auch unionsrechtskonforme positive Ordnung des Rundfunks Verantwortlichen - bei einer Fortentwicklung der Finanzierung des öffentlichrechtlichen Rundfunks befassen müssen.

Diese Analyse kann und muss aufbauen auf der bisherigen europarechtlichen Einordnung der Finanzierung des öffentlich-rechtlichen Rundfunks in Deutschland. Sie weist aber bereits deshalb hierüber hinaus, weil umfänglich indexierungsbasierte Formen der Finanzierung des öffentlich-rechtlichen Rundfunks in den bisherigen Finanzierungsmethoden öffentlich-rechtlichen Rundfunks in den Mitgliedstaaten der EU zwar - in unterschiedlicher Ausformung im Detail ${ }^{7}$ - bekannt sind (namentlich auch im Vereinigten Königreich, dessen

2 Zitiert in Dokumentation „Auftrag und Finanzierung des öffentlich-rechtlichen Rundfunks“, Medienkorrespondenz 7/2019, S. 12.

3 Vgl. zuletzt die Gutachten von Cornils (2019) und Hirschle (2019).

4 Vgl. aus dem Kreis der Chefs der Staats- und Senatskanzleien z.B. Hoff (2017), Lennartz (2019), Mielke (2019), Robra (2018).

5 Vgl. zu unionsrechtlichen Aspekten auch Cornils (2019), S. $28 \mathrm{ff}$.

6 Unter unionsrechtlichem Blickwinkel unbeachtlich ist dabei, auf welchen Index sich eine solche „Vollindexierung“ stützen würde - ob auf den seitens des Statistischen Bundesamtes monatlich veröffentlichten Verbraucherpreisindex oder den nicht warenkorbgebundenen BIP-Deflator. In Frage käme zwar auch ein dritter, bislang noch nicht genutzter Index. Dessen Entwicklung dürfte allerdings den Übergang zu einer Vollindexierung zusätzlich hinausschieben und wäre mit nicht unerheblichen Mehrkosten verbunden. Probleme einer rundfunkrechtsspezifischen Methodik der Datenermittlung haben sich im Übrigen bereits im Zusammenhang mit der Geschichte des § $27 \mathrm{RStV}$ gezeigt.

7 Vgl. hierzu Künzler, Puppis, Schweizer \& Studer (2013), S. 10 f. (für Belgien), S. 16 (für Finnland), S. 17 f. (für Frankreich), S. 21 (für Irland) und S. 27 (für die Niederlande); Perten, (2014), S. 166 ff. 
Austritt aus der EU immer noch bevorsteht), ${ }^{8}$ allerdings weder in der Aufsichtspraxis der Europäischen Kommission noch in der juristischen Kontrolle durch die Gerichte der EU (Europäischen Gerichtshof und Gericht der EU bzw. dessen Vorläufer, das Gericht Erster Instanz der EG) eine vertiefte Würdigung auf die Unionsrechtskonformität erfahren haben. ${ }^{9}$

Dies birgt Chancen wie Risiken in gleicher Weise: Die Chancen liegen nicht zuletzt in einer Vorreiterrolle Deutschlands bei erhöhter Planungssicherheit ${ }^{10}$ und verringerter Möglichkeit von politischer Einflussnahme ${ }^{11}$ - beides Instrumente der finanziellen Absicherung eines staatsunabhängigen öffentlich-rechtlichen Rundfunks. Dies ist in rechtsvergleichender Perspektive auch deshalb besonders bedeutsam, weil eine solche Absicherung jüngst Gegenstand kritischer Reflexion mit Blick auf Rechtsentwicklungen in Staaten war, die bislang als safe harbours für einen funktionsfähigen und regulatorisch gestützten freien öffentlich-rechtlichen Rundfunk galten. ${ }^{12}$

Die Risiken prägen die nachfolgenden Ausführungen. Mangels gefestigter europarechtlicher Praxis verdichtet sich allerdings - dies kann als wesentliches Ergebnis vorweggenommen werden - keines der Risiken zu einem apriorischen „No go“ für den Umstieg zu einer System einer umfassenden Indexierung der Entwicklung der Beitragshöhe.

Es bleibt politischer Entscheidung i.S. einer medienrechtspolitischen und finanzverfassungsrechtlichen Entwicklungsprognose überlassen, ob der behauptete Nutzen einer solchen „Vollindexierung“ als höher eingestuft wird, als die (nicht nur europa-) rechtlichen Risiken. ${ }^{13}$ Die nachfolgenden Ausführungen zeigen Leitplanken auf, wie die unionsrechtlichen Risiken bei einem Übergang zu einer umfassenden Indexierung im System der Bei-

$8 \mathrm{Zu}$ den Auswirkungen des Brexit im audiovisuellen Bereich vgl. z.B. Burggraf \& Wiesner (2019), Cole, Ukrow \& Etteldorf (2018).

9 Insoweit ist die unionsrechtliche Debatte weniger durch höchstrichterliche Rechtsprechung (mit-) bestimmt als die verfassungsrechtliche Debatte, in der eine Entscheidung des BVerfG deutliche Offenheit für einen Systemwechsel signalisiert: Dieses hatte 2007 ausgeführt: „Wie das Verfahren der Gebührenfestsetzung im Rahmen dieser grundrechtlichen Vorgaben im Einzelnen ausgestaltet wird, ist Sache gesetzgeberischer Entscheidung. So spricht etwa aus verfassungsrechtlicher Sicht nichts gegen die Verwendung indexgestützter Berechnungsmethoden zur Berücksichtigung der allgemeinen und der rundfunkspezifischen Kostenentwicklung. Auch einer weiterreichenden Umstrukturierung des Verfahrens im Sinne einer Vollindexierung... stehen von Verfassungs wegen grundsätzlich keine Hindernisse entgegen, zumal ein derartiges Vorgehen in besonderem Maße geeignet ist, das Gebührenfestsetzungsverfahren gegen sachfremde Einflüsse abzuschirmen“, BVerfGE 119, 181 (224). Kritisch hierzu Cornils (2019), S. 8 ff.; Hain, JZ 2008, 128 (133).

10 Vgl. zu dieser Zweckrichtung der Indexierung als ,Instrument einer vorausschauenden Finanzplanung“" Cornils (2019), S. 5; Vesting, DVB1. 1991, 857 (858).

11 Vgl. zu dieser Zweckrichtung Knothe \& Schwalba, ZUM 1999, 459 (467).

12 Vgl. Council of Europe (2019), S. $28 \mathrm{ff}$.

13 Schon vor diesem Hintergrund fortdauernder medienrechtspolitischer Gestaltungsmacht und spielräume nicht nur zum „wie“, sondern bereits zum „ob“ eines Systemwechsels verzichtet dieser Beitrag auf staatsvertragliche Novellierungsvorschläge für den Rundfunkfinanzierungsstaatsvertrag unter Einbindung einer „Vollindexierung“ des Rundfunkbeitrags. 
tragsfinanzierung minimiert werden können und weisen auch auf rechtspolitische Handlungsoptionen hin, die sich nicht zuletzt im Zuge der Neukonstituierung von EU-Organen im Nachgang zu den Wahlen zum Europäische Parlament im Mai diesen Jahres eröffnen.

\section{Der unionsrechtliche Rahmen der Beurteilung der Rechtskonformität einer Vollindexierung der Fortschreibung des Rundfunkbeitrags}

Die Beurteilung, ob eine umfassend indexgestützte Methode der Anpassung des Rundfunkbeitrages ${ }^{14}$ zur Finanzierung des öffentlich-rechtlichen Rundfunks (im Folgenden: ,Vollindexierung") mit dem Unionsrecht in Einklang steht, hat vom primärrechtlichen Normmaterial auszugehen. Hierzu zählen namentlich

- die Vorgaben des AEUV zur Wettbewerbsverfassung der EU, ${ }^{15}$ namentlich die Bestimmungen zur Beihilfenaufsicht, dort insbesondere auch Art. 107 Abs. 3 lit. d AEUV, ${ }^{16}$ sowie die Bestimmungen zu Dienstleistungen von allgemeinem wirtschaftlichem Interesse, ${ }^{17}$

- die kulturpolitische Querschnittsklausel des Art. 167 Abs. 4 AEUV, ${ }^{18}$ die auch für die Art und Weise der Kontrollausübung seitens der EU-Organe gegenüber und mit Blick auf öffentlich-rechtliche Rundfunkanstalten bedeutsam ist, sowie

- das sog. Amsterdamer Protokoll zum öffentlich-rechtlichen Rundfunk. ${ }^{19}$

Auf der Grundlage und in Ausformung dieser primärrechtlichen Regelungen hat die Europäische Kommission als Hüterin der Verträge eine Reihe von Rechtsakten sekundären Unionsrechts im Bereich der Beihilfeaufsicht erlassen, die auch für die Finanzierung des öffentlich-rechtlichen Rundfunks in Deutschland bedeutsam sind oder diesen sogar ausschließlich im Blick haben. Zu beachten sind insoweit:

- die Verordnung (EU) 2015/1589 des Rates vom 13. Juli 2015 über besondere Vorschriften für die Anwendung von Artikel 108 des Vertrags über die Arbeitsweise der Europäischen Union, 20

- die Richtlinie 2006/111/EG der Kommission vom 16. November 2006 über die Transparenz der finanziellen Beziehungen zwischen den Mitgliedstaaten und den öffentlichen

14 Zum Systemwechsel vom Gebühren- zum Beitragsmodell vgl. ausführlich z.B. Wagner (2011).

15 Vgl. hierzu in medienbezogener Perspektive Jungheim (2012), S. 249 ff.

16 Vgl. hierzu z.B. Germelmann (2013), S. 421 ff.; Kruse, EWS 1996, 113 (115); Müller (2014), S. $412 \mathrm{ff}$.

17 Vgl. hierzu z.B. Jung (2018), S. 28 ff.; Melcher (2016), S. 49 ff.; Müller (2014), S. 452 ff.

18 Vgl. hierzu z.B. Frenz (2007), Rn. 4093 ff.; Ress/Ukrow, in: Grabitz, Hilf \& Nettesheim (Hrsg.) (2018), Art. 167 AEUV Rn. $148 \mathrm{ff}$.

19 Vgl. hierzu z.B. Knodel (2018), S. 46 ff.; Stulz-Herrnstadt (2004), S. 266 ff.

20 AB1. EU 2015 Nr. L 248/9. 
Unternehmen sowie über die finanzielle Transparenz innerhalb bestimmter Unternehmen, ${ }^{21}$

- der Beschluss der Kommission über die Anwendung von Artikel 106 Absatz 2 des Vertrags über die Arbeitsweise der Europäischen Union auf staatliche Beihilfen in Form von Ausgleichsleistungen zugunsten bestimmter Unternehmen, die mit der Erbringung von Dienstleistungen von allgemeinem wirtschaftlichem Interesse betraut sind, ${ }^{22}$

- die Mitteilung der Kommission über die Anwendung der Beihilfevorschriften der Europäischen Union auf Ausgleichsleistungen für die Erbringung von Dienstleistungen von allgemeinem wirtschaftlichem Interesse, ${ }^{23}$

- die Mitteilung der Kommission über die Anwendung der Vorschriften über staatliche Beihilfen auf den öffentlich-rechtlichen Rundfunk aus $2009^{24}$ und

- die Entscheidung der Kommission vom 24. April 2007,25 der sog. Beihilfekompromiss. ${ }^{26}$

Der Verordnung (EU) Nr. 360/2012 der Kommission vom 25. April 2012 über die Anwendung der Artikel 107 und 108 des Vertrags über die Arbeitsweise der Europäischen Union auf De-minimis-Beihilfen an Unternehmen, die Dienstleistungen von allgemeinem wirtschaftlichem Interesse erbringen, ${ }^{27}$ kommt demgegenüber mit Blick auf den Grenzwert von 500.000 Euro für eine Einordnung einer Beihilfe als geringfügig von vornherein keine Bedeutung zu, da dieser Grenzwert bei dem Aufkommen aus dem Rundfunkbeitrag erheblich überschritten wird. ${ }^{28}$ Und der Rahmen der Europäischen Union für staatliche Beihilfen in Form von Ausgleichsleistungen für die Erbringung öffentlicher Dienstleistungen $(2011)^{29}$ gilt nach einer ausdrücklichen Festlegung in diesem Regelwerk nicht für den öffentlichrechtlichen Rundfunk. ${ }^{30}$ Für diesen verweist der Rahmen vielmehr auf die Mitteilung der Kommission über die Anwendung der Vorschriften über staatliche Beihilfen auf den öffentlich-rechtlichen Rundfunk.

Neben dem primären und sekundären Unionsrecht kommt schließlich der Judikatur der europäischen Gerichte - EuGH und EuG - zentrale Steuerungswirkung im Spannungsfeld

21 AB1. EU 2006 Nr. L 318/17.

22 ABl. EU 2012 Nr. L 7/3.

23 AB1. EU 2012 Nr. C 8/4.

24 AB1. EU 2009 Nr. C 257/1.

25 Europäische Kommission (2007),Tz. 216.

26 Vergleichbare Entscheidungen der Kommission zu Finanzierungssystemen für Rundfunkveranstalter mit public service-Auftrag gibt es für zahlreiche EU-Mitgliedstaaten; vgl. überblicksartig Oster (2017), S. $509 \mathrm{ff}$.

27 AB1. EU 2012 Nr. L 114/8.

28 Die Erträge aus der Rundfunkgebühr beliefen sich in 2016, dem letzten im aktuellsten Finanzbericht der ARD erfassten Jahr, auf 5.571 Mio. Euro; vgl. ARD (2018), S. 81. Beim ZDF beliefen sich diese Erträge auf 1.884 Mio. Euro; vgl. ZDF (2018).

29 ABl. EU 2012 Nr. C 8/15.

30 A.a.O., Tz. 8 Satz 2. 
von unionaler Wettbewerbsordnung und nationaler Rundfunkfinanzordnung zu. Auch wenn diese Judikatur rechtliche Bindungswirkung jeweils nur im konkreten Einzelfall entfaltet, sind Rechtsprechungslinien von EuG und EuGH dennoch auch über die Klärung von Rechtsfragen in einem konkreten Einzelfall und die damit verbundene Bindungswirkung inter partes hinaus als Auslegungsinstrumente erga omnes bedeutsam. ${ }^{31}$ Beachtung verdient damit fortdauernd nicht nur die jüngste Entscheidung des EuGH zum Systemwechsel auf eine Beitragsfinanzierung des öffentlich-rechtlichen Rundfunks in Deutschland, ${ }^{32}$ sondern insbesondere auch das Urteil des Europäischen Gerichtshofs in der Rechtssache Altmark Trans. ${ }^{33}$

\section{Zur Bedeutung der primärrechtlichen Wettbewerbsordnung der EU}

\section{Zur Einordnung des Rundfunkbeitrags als Beihilfe i.S. des Unionsrechts}

Die Beihilfeneigenschaft ist Voraussetzung dafür, dass eine Maßnahme wie z.B. die Finanzierung öffentlich-rechtlichen Rundfunks dem Aufsichtsregime des Art. 107 AEUV unterliegt. Fehlt diese Eigenschaft, so besteht keine Pflicht des Staates zur Notifikation an die Kommission gemäß Art. 108 Abs. 3 Satz 1 AEUV, kein Genehmigungsvorbehalt und kein Durchführungsverbot i.S. des Art. 108 Abs. 3 Satz 3 AEUV. Erst bei Vorliegen des BeihilfeCharakters einer staatliche Maßnahme bedarf es einer Prüfung dieser Maßnahme darauf, ob sie mit dem Binnenmarkt vereinbar ist, im Rahmen eines beihilfeaufsichtsrechtlichen Verfahrens.

Nach ständiger Rechtsprechung des EuGH verlangt die Qualifizierung als mit dem Binnenmarkt unvereinbare „Beihilfe“ im Sinne von Art. 107 Abs. 1 AEUV, dass alle vier in dieser Bestimmung genannten Voraussetzungen erfüllt sind: Erstens muss es sich um eine staatliche Maßnahme oder eine Maßnahme unter Inanspruchnahme staatlicher Mittel handeln. Zweitens muss sie geeignet sein, den Handel zwischen Mitgliedstaaten zu beeinträchtigen. Drittens muss dem Begünstigten durch sie ein Vorteil gewährt werden. Viertens muss sie den Wettbewerb verfälschen oder zu verfälschen drohen. ${ }^{34}$ In Bezug auf die erste Voraussetzung der unmittelbaren oder mittelbaren Gewährung des Vorteils aus staatlichen Mitteln entspricht es ständiger Rechtsprechung, dass auch Maßnahmen, bei denen keine staatlichen Mittel übertragen werden, unter den Begriff der „Beihilfe“ im Sinne von Art. 107 Abs. 1 AEUV fallen können; durch den Begriff der Maßnahme ,aus staatlichen Mitteln“

$31 \mathrm{Zu}$ einer Bindungswirkung erga omnes vgl. Gaitanides, in: von der Groeben, Schwarze \& Hatje (Hrsg.) (2015), Art. 267 AEUV Rn. 90 ff.; Wusterhausen (2016), S. 57 ff.

32 EuGH, Rs. C-492/17 [2018] Rittinger u.a.

33 EuGH, Rs. C-280/00 [2003] Altmark Trans und Regierungspräsidium Magdeburg.

34 Vgl. EuGH, Rs. C-280/00 [2003] Altmark Trans und Regierungspräsidium Magdeburg [75]; Rs. C-206/06 [2008] Essent Netwerk Noord u.a. [63-64]; Rs. C-262/12 [2013] Vent De Colère u.a. [15] (jeweils m.w.N.). 
sollen nicht nur unmittelbar vom Staat gewährte Vorteile, sondern auch Vorteile einbezogen werden, die durch von ihm zur Durchführung der Beihilferegelung errichtete oder damit beauftragte öffentliche oder private Einrichtungen gewährt werden. ${ }^{35}$ Art. 107 Abs. 1 AEUV erfasst dabei sämtliche Geldmittel, die die öffentlichen Stellen tatsächlich zur Unterstützung der Unternehmen verwenden können, ohne dass es darauf ankommt, dass diese Mittel dauerhaft zum Vermögen des Staates gehören. Auch wenn die der fraglichen Maßnahme entsprechenden Beträge nicht auf Dauer dem Staat gehören, genügt folglich der Umstand, dass sie ständig unter staatlicher Kontrolle und somit den zuständigen nationalen Behörden zur Verfügung stehen, damit sie als ,staatliche Mittel“ qualifiziert werden können. ${ }^{36}$

An der Beurteilung, ob eine Beihilfeeigenschaft besteht, sind - vorbehaltlich des ,letzten Wortes", das die Gerichte der EU haben - die Regierung des jeweiligen Mitgliedstaates (bzw. im Falle einer Länderzuständigkeit für die betreffende Maßnahme in Deutschland nach den Maßgaben des Art. 23 GG und des Gesetzes über die Zusammenarbeit von Bund und Ländern in Angelegenheiten der Europäischen Union (EUZBLG) vom 12. März $1993^{37}$ - die Regierungen der deutschen Länder), die staatlichen Gerichte des jeweiligen Mitgliedstaates und die Europäische Kommission beteiligt. Von der Beurteilung durch die Regierung hängt ab, ob eine Notifikation an die Kommission erfolgt. In Zweifelsfällen ist eine vorsorgliche Notifikation möglich, ${ }^{38}$ um einen Beschluss der Kommission gemäß Art. 4 Abs. 2 der Verfahrensordnung ${ }^{39}$ einzufordern, dass die Maßnahme keine Beihilfe ist.

Die deutschen Länder stehen im Zuge eines etwaigen Übergangs zu einer „Vollindexierung“" vor der Entscheidung, ob sie diesen Weg der prophylaktischen Einordnung i.S. einer Risikovorsorge beschreiten oder in Anknüpfung an ihre bisherige Haltung, dass es sich bei der Finanzierung des öffentlich-rechtlichen Rundfunks nicht um eine Beihilfe handelt, oder auf der Grundlage einer Position, dass es sich hierbei zumindest um eine bisherige Beihilfe handelt, deren Charakter durch den Umstieg zu einer „Vollindexierung“ nicht gewandelt wird, von einer Notifikation absehen. Ein solcher Verzicht auf eine Notifikation birgt namentlich Risiken, die aus einer Verletzung des Durchführungsverbotes nach Art. 108 Abs. 3

35 Vgl. insbesondere EuGH, Rs. C-379/98 [2001] PreussenElektra [58]; Rs. C-482/99 [2002] Frankreich/Kommission [36]; Rs. C-677/11 [2013] Doux Élevage und Coopérative agricole UKL-ARREE [26, 34]; Rs. C-262/12 [2013] Vent De Colère u.a. [19-20]; Rs. C-657/15 P [2017] Viasat Broadcasting UK/TV 2/Danmark [35-45].

36 Vgl. insbesondere EuGH, Rs. C-482/99 [2002] Frankreich/Kommission [37]; Rs. C-206/06 [2008] Essent Netwerk Noord u.a. [70]; Rs. C-677/11 [2013] Doux Élevage und Coopérative agricole UKL-ARREE [35]; Rs. C-262/12 [2013] Vent De Colère u.a. [21]; Rs. C-657/15 P [2017] Viasat Broadcasting UK/TV 2/Danmark [38-39].

37 BGB1. 1993 I S. 313, zuletzt geändert durch Artikel 1 des Gesetzes vom 22. September 2009 (BGB1. I S. 3031).

38 Vgl. Götz, in: Dauses/Ludwigs (Hrsg.), Handbuch des EU-Wirtschaftsrechts, Stand: Januar 2019, H.III Rn. 48.

39 Verordnung (EU) 2015/1589 des Rates vom 13. Juli 2015 über besondere Vorschriften für die Anwendung von Artikel 108 des Vertrags über die Arbeitsweise der Europäischen Union, ABl. EU 2015 Nr. L 248/9. 
Satz 3 AEUV entstehen können. Die Risiken einer Beurteilung, die sich später bei der Europäischen Kommission und den Gerichten der EU nicht durchsetzen wird, betreffen nicht nur die öffentlich-rechtlichen Rundfunkanstalten. Eine solche Divergenz in der Beurteilung kann auch das auf Kooperation gerichtete Verhältnis ${ }^{40}$ zwischen dem bislang die funktions- und bedarfsgerechte Finanzierung des öffentlich-rechtlichen Rundfunks zuverlässig sichernden Bundesverfassungsgericht ${ }^{41}$ und den auch die Wettbewerbsordnung der EU stützenden Gerichten der EU belasten. Auch vor diesem Hintergrund ist seitens der deutschen Länder eine sorgfältige Abwägung geboten. ${ }^{42}$

Deutschland hat - auch im Zusammenhang mit dem sog. Beihilfekompromiss aus $2007^{43}$ - stets den Beihilfecharakter des deutschen Systems der Finanzierung des öffentlich-rechtlichen Rundfunks aus Mitteln der Rundfunkgebühr bestritten.

Die Kommission hat demgegenüber die Finanzierung des öffentlich-rechtlichen Rundfunks in ständiger Entscheidungspraxis - nach einer Praxis der Ablehnung der Beihilfequalität von mitgliedstaatlicher Finanzierung öffentlich-rechtlicher Rundfunkanstalten bis in die 1990er Jahre hinein ${ }^{44}$ - seit Beginn der 2000er Jahre „im Normalfall“ als eine Beihilfe zugunsten der öffentlichen Rundfunkveranstalter eingeordnet, allerdings auf die Notwendigkeit der Prüfung im Einzelfall verwiesen. ${ }^{45}$ Hieran hat sich auch im Übergang von der Gebühren- zur Beitragsfinanzierung nichts geändert. ${ }^{46}$

Nach der Bestätigung dieses Ansatzes in der Judikatur des EuGH spricht nichts dafür, dass sich an der Einordnung der Rundfunkbeitragsfinanzierung als Beihilfe durch Kommission und Gerichte der EU bei einem Übergang zu einer „Vollindexierung“ etwas ändern wird: Für die Europäische Kommission sind die Einnahmen aus Rundfunkgebühren oder -beiträgen staatliche Mittel, weil sie ihre Grundlage in staatlichen Hoheitsakten haben und unter staatlicher Kontrolle stehen. Die Rechtsprechung der Gerichte der EU stützt diese Einordnung. ${ }^{47}$

Streitig könnte bei dem Übergang zu einer umfassend indexgestützten Methode erneut und verstärkt werden, ob die öffentliche Finanzierung auch danach einen Ausgleich der zur Erfüllung gemeinwirtschaftlicher Verpflichtungen gemachten Aufwendungen darstellt und deshalb (auch bei diesem Übergang) die beitragsgestützte Finanzierung keine vorteilverschaffende Begünstigung darstellt. Insoweit dürfte den sog. Altmark-Trans-Kriterien, die

40 Vgl. BVerfGE 89, 155 (175) (st. Rspr.); hierzu sowie z.B. Hirsch, NJW 1996, 2457 (2462); Nunner (2009), S. 159 ff.; Schliesky (2004), S. 378 ff.

41 Vgl. hierzu z.B. Hahn (2010), S. 21 ff:; Hoffmann (2016), S. 49 ff.

42 Vgl. hierzu auch Götz, in: Dauses \& Ludwigs (Hrsg.) (2019), H.III Rn. 48.

43 Vgl. hierzu Abschnitt VII sowie Europäische Kommission (2007), Tz. 81 ff.

44 Vgl. hierzu Frenz (2007), Rn. 485.

45 Vgl. Kommission der EG (2001), Tz. 17. Für Deutschland vgl. Europäische Kommission (2007), Tz. $141 \mathrm{ff}$.

46 Vgl. den Hinweis in den Schlussanträgen des Generalanwalts Campos Sánchez-Bordona in der Rs. C-492/17 [2018] Rittinger u.a., Tz. $41 \mathrm{f}$.

47 Vgl. Europäische Kommission (2007), Tz. 142 ff. m.w.N. 
zunächst in der Judikatur des $\mathrm{EuGH}^{48}$ entwickelt wurden und sodann in den die beihilfeaufsichtsrechtliche Entscheidungspraxis der Europäischen Kommission leitenden Rechtsakten aufgegriffen wurden, ${ }^{49}$ besondere Bedeutung zukommen.

Beihilfeaufsicht findet (auch) im Bereich der Kontrolle der Finanzierung des öffentlichrechtlichen Rundfunks allerdings nicht zwingend über ein Anmelde- und Genehmigungsverfahren statt. Ein solches Verfahren gilt nach der Systematik des AEUV nur bei neuen Beihilfen. In Bezug auf bestehende Beihilferegelungen sieht Art. 108 Abs. 1 AEUV dagegen ein auf Kooperation aufbauendes Verfahren vor: Hier „überprüft (die Kommission) fortlaufend in Zusammenarbeit mit den Mitgliedstaaten die in diesen bestehenden Beihilferegelungen. Sie schlägt ihnen die zweckdienlichen Maßnahmen vor, welche die fortschreitende Entwicklung und das Funktionieren des Binnenmarkts erfordern“. Ob es sich bei einer Vollindexierung der Rundfunkbeitragsfinanzierung des öffentlich-rechtlichen Rundfunks noch um eine solche bestehende Beihilfe handelt, ist - wie im Einzelnen noch ausgeführt wird ${ }^{50}$ - schon an sich nicht unionsrechtlich zweifelsfrei prognostizierbar; die diesbezüglichen Risikofaktoren wachsen im Übrigen in dem Maße, in dem dieser Systemwechsel mit Änderungen in der Auftragsdefinition in Richtung auf eine größere definitorische Eigenbefähigung und -verantwortung des öffentlich-rechtlichen Rundfunks selbst verbunden sind. Denn solche Änderungen beeinträchtigen das System der effizienten Eigen- und Fremdkontrolle der Zweckhaftigkeit einer Beihilfe als Ausprägung des unionsrechtlichen Transparenzgebotes.

\section{Zur Bedeutung der Sonderregeln für Dienstleistungen von allgemeinem wirtschaftlichem Interesse}

\section{a) Einführung}

Art. 106 Abs. 2 AEUV enthält zwar keine generelle Bereichsausnahme für Dienstleistungen von allgemeinem wirtschaftlichem Interesse (DAWI) von den Wettbewerbsregeln des AEUV und damit auch nicht von der unionalen Beihilfenaufsicht. Die Regelung nimmt die DAWI allerdings von der Anwendung des Beihilfeaufsichtsregimes der EU aus, soweit die Anwendung die Erfüllung der den Unternehmen ,übertragenen besonderen Aufgabe” rechtlich oder tatsächlich verhindern würde. ${ }^{51}$ Die Herstellung praktischer Konkordanz zwischen unionaler Beihilfeaufsicht und mitgliedstaatlicher Souveränität in der Betrauung von Unternehmen mit DAWI ist eine fortdauernde Kompetenz- und Machtfrage zwischen der EU und

48 EuGH, Rs. C-280/00, [2003] Altmark Trans GmbH und Regierungspräsidium Magdeburg.

49 Vgl. hierzu Abschnitt II.

50 Vgl. hierzu Abschnitt VII.3.

51 Vgl. Jung, in: Calliess \& Ruffert (2016), Art. 106 AEUV Rn. 56 ff.; Khan, in: Geiger, Khan \& Kotzur (2017), Art. 106 AEUV Rn. 8 ff.; Klotz, in: von der Groeben, Schwarze \& Hatje (2015), Art. 106 AEUV Rn. 56 ff.; Koenig \& Paul, in: Streinz (2018), Art. 106 AEUV Rn. 36 ff.; Mestmäcker \& Schweitzer (2014), S. 970 ff. 
ihren Mitgliedstaaten. ${ }^{52}$ Das Austarieren zwischen diesen beiden Polen kann nicht zuletzt in Zeiten personeller Umbrüche bei den EU-Organen Kommission und Parlament immer wieder aufs Neue evaluiert und auch unter Berücksichtigung allgemeiner integrationspolitischer Erwägungen angepasst werden.

In einer über mehrere Jahrzehnte aufgebauten positiven Bewertung, in dem die Dienstleistungen der Daseinsvorsorge seitens der Europäischen Kommission als „Schlüsselelement des europäischen Gesellschaftsmodells“,53 als „unverzichtbarer Bestandteil des europäischen Gesellschaftsmodells“"54 und als „,eine der Grundsäulen..., auf denen das europäische Gesellschaftsmodell gründet“, 55 anerkannt wurden, wurde der „Stellenwert, den Dienste von allgemeinem wirtschaftlichem Interesse innerhalb der gemeinsamen Werte der Union einnehmen“, in Art. 14 Satz 1 AEUV primärrechtlich anerkannt ${ }^{56}$ und auf dieser Grundlage zugleich die Verpflichtung für EU wie Mitgliedstaaten verankert, „im Rahmen ihrer jeweiligen Befugnisse im Anwendungsbereich der Verträge dafür Sorge (zu tragen), dass die Grundsätze und Bedingungen, insbesondere jene wirtschaftlicher und finanzieller Art, für das Funktionieren dieser Dienste so gestaltet sind, dass diese ihren Aufgaben nachkommen können“. Diese Grundsätze und Bedingungen werden nach Art. 14 Satz 2 AEUV vom Europäischen Parlament und vom Rat durch Verordnungen festgelegt - „unbeschadet der Zuständigkeit der Mitgliedstaaten, diese Dienste im Einklang mit den Verträgen zur Verfügung zu stellen, in Auftrag zu geben und zu finanzieren“.

Im „Protokoll (Nr. 26) über Dienste von allgemeinem Interesse“ zum AEUV, ${ }^{57}$ das im Range dem AEUV gleichsteht, wird in dessen Art. 1 diese mitgliedstaatliche Gestaltungsmacht sogar selbst zum „Grundwert“ der EU erklärt: Zu den ,gemeinsamen Werten der Union in Bezug auf Dienste von allgemeinem wirtschaftlichem Interesse" i.S. des Art. 14 AEUV zählen danach insbesondere ,die wichtige Rolle und der weite Ermessensspielraum der nationalen, regionalen und lokalen Behörden in der Frage, wie Dienste von allgemeinem wirtschaftlichem Interesse auf eine den Bedürfnissen der Nutzer so gut wie möglich entsprechende Weise zur Verfügung zu stellen, in Auftrag zu geben und zu organisieren sind; die Vielfalt der jeweiligen Dienstleistungen von allgemeinem wirtschaftlichem Interesse und die Unterschiede bei den Bedürfnissen und Präferenzen der Nutzer, die aus unterschiedlichen geografischen, sozialen oder kulturellen Gegebenheiten folgen können, (so-

52 Vgl. auch Götz, in: Dauses \& Ludwigs (2019), H.III Rn. 15; Storr, in: Birnstiel, Bungenberg \& Heinrich Kap. 1 Rn. 243 f.; von Komorowski, EuR 2015, 310 (322 ff.).

53 Kommission der Europäischen Gemeinschaften, Mitteilung „Leistungen der Daseinsvorsorge in Europa“" (2001/C 17/04), ABI. 2001 C 17/4.

54 Kommission der Europäischen Gemeinschaften, Grünbuch zu den Dienstleistungen von allgemeinem Interesse, KOM (2003) 270 endg., Rn. 2.

55 Kommission der Europäischen Gemeinschaften, Weißbuch zu Dienstleistungen von allgemeinem Interesse, KÖM [2004] 374 endg., S. 4.

56 Vgl. hierzu Krajewski (2011), S. 178 ff.

57 ABl. EU 2008 Nr. 115/308. 
wie) ein hohes Niveau in Bezug auf Qualität, Sicherheit und Bezahlbarkeit, Gleichbehandlung und Förderung des universellen Zugangs und der Nutzerrechte“" ${ }^{58}$

Vor diesem Hintergrund ist zwar im Ansatz unstreitig, dass die Mitgliedstaaten nach ihrem Ermessen darüber befinden, welche Dienstleistungen sie als solche von allgemeinem wirtschaftlichem Interesse organisieren. Das Gericht 1. Instanz der EG hat 2008 auf diese Zuständigkeit der Mitgliedstaaten sowie darauf hingewiesen, dass das Unionsrecht keine präzise und vollständige Definition des Begriffes aufweist. Es hat allerdings zugleich eine unionale Kontrollkompetenz anerkannt, die wiederum ihrerseits im Lichte des primärrechtlichen Normenmaterials begrenzt ist: „die Kontrolle, zu der die Gemeinschaftsorgane in Bezug auf die Ausübung des mitgliedstaatlichen Ermessens bei der Bestimmung der Dienstleistungen von allgemeinem wirtschaftlichem Interesse befugt sind, (ist) auf die Suche nach einem offenkundigen Beurteilungsfehler beschränkt". ${ }^{59}$ Dieser von den Unionsorganen beanspruchte Kontroll- und Korrekturvorbehalt hat in der Vergangenheit bereits zu einer Begrenzung der Ermessensausübung der Mitgliedstaaten außerhalb des Rundfunksektors geführt. ${ }^{60}$

Innerhalb des Bereichs der Daseinsvorsorge kommt dem öffentlich-rechtlichen Rundfunk seit seinem Bestehen in vielerlei Hinsicht eine besondere Bedeutung zu. Sie resultiert auch völker- ${ }^{61}$ europarats- ${ }^{62}$ und unionsrechtlich anerkannt ${ }^{63}$ insbesondere aus der Funktion des öffentlich-rechtlichen Rundfunks für die Information und Meinungsbildung, die

58 Nach Artikel 2 des Protokolls berühren die Bestimmungen von EUV und AUV zudem ,in keiner Weise die Zuständigkeit der Mitgliedstaaten, nichtwirtschaftliche Dienste von allgemeinem Interesse zur Verfügung zu stellen, in Auftrag zu geben und zu organisieren“.

59 EuG, Rs. T-289/03 [2008] BUPA [169].

60 Besondere Aufmerksamkeit hat in Deutschland insoweit das Verfahren in Sachen Zweckverband Tierkörperbeseitigung in Rheinland-Pfalz, im Saarland, im Rheingau-Taunus-Kreis und im Landkreis Limburg-Weilburg gefunden: Hier verweigerte die Europäische Kommission dem Zweckverband die Anerkennung, bei der ihm übertragenen Beseitigung von Falltieren und Schlachtabfall gemeinwirtschaftliche Verpflichtungen wahrzunehmen (Beschluss v. 25. April 2012 über die staatliche Beihilfe SA. 25051, ABI. 2012 L 236/1, Tz. 156 ff.). Das Gericht der EU ist mit Urteil vom 16. Juli 2014 (Rs. T-309/12, Zweckverband Tierkörperbeseitigung/Kommission) dieser Einschätzung nicht entgegengetreten.

61 Vgl. Art. 6 Abs. 1 und Abs. 2 Buchst. h) des UNESCO-Übereinkommens zum Schutz und zur Förderung der Vielfalt kultureller Ausdrucksformen, das mit dem Beschluss 2006/515/EG des Rates vom 18.5.2006 (ABl. EU 2006 Nr. L 201/15) für die EU angenommen wurde. Zur Bedeutung des öffentlich-rechtlichen Rundfunks im Lichte dieses Übereinkommens vgl. Lutzhöft (2012), S. 291 f.; Sucker (2018), S. 88 f.

62 Vgl. u.a. die Empfehlung CM/Rec(2007)3 des Ministerkomitees an die Mitgliedstaaten betreffend den Auftrag der öffentlich-rechtlichen Medien in der Informationsgesellschaft, angenommen am 31. Januar 2007 beim 985. Treffen der Ständigen Vertreter. Vgl. im Übrigen - auch zur Rechtsprechung des Europäischen Gerichtshofs für Menschenrechte - Cappello (2015), S. 11 ff.

63 Die Bedeutung des öffentlich-rechtlichen Rundfunks für das soziale, demokratische und kulturelle Leben in der EU wurde auch in der Entschließung des Rates und der im Rat vereinigten Vertreter der Regierungen der Mitgliedstaaten vom 25. Januar 1999 über den öffentlich-rechtlichen Rundfunk (ABl. EG 1999 Nr. C 30/1) bekräftigt. 
Werte-Vermittlung und damit das Funktionieren der demokratischen Gesellschaft: Der öffentlich-rechtliche Rundfunk ,,ist mit keiner öffentlichen Dienstleistung in irgendeinem anderen Wirtschaftszweig zu vergleichen. Keine andere Dienstleistung erreicht so weite Kreise der Bevölkerung, versorgt sie zugleich mit so vielen Informationen und Inhalten und verbreitet und beeinflusst dadurch sowohl die Ansichten Einzelner als auch die öffentliche Meinung. Darüber hinaus wird der Rundfunk im Allgemeinen als sehr zuverlässige Informationsquelle wahrgenommen und stellt für einen beträchtlichen Teil der Bevölkerung die Hauptinformationsquelle dar. Er bereichert damit die öffentliche Diskussion und trägt letztendlich zu einer angemessenen Beteiligung aller Bürger am öffentlichen Leben bei.“

Diese Einordnung in der aktuell geltenden Rundfunkmitteilung der Europäischen Kommission aus $2009^{64}$ ist ungeachtet der Wandlungen im Bereich ökonomischer, technischer sowie mediennutzungsbezogener Rahmenbedingungen der Tätigkeiten des öffentlich-rechtlichen Rundfunks und der wachsenden Einflussnahme neuer Medienakteure wie Plattformen und Intermediäre auf den demokratischen Meinungs- und Willensbildungsprozess fortdauernd im Kern zutreffend. ${ }^{65}$

Da allerdings im Zeitalter von Digitalisierung und Globalisierung auch die öffentlichrechtlichen Rundfunkanstalten die herkömmlichen Übertragungswege und die traditionellen Hörfunk- und Fernseh-Dienste schon seit längerem nicht mehr ausschließlich betreiben und z.B. durch umfangreiche Auftritte auch im Medium Internet Präsenz zeigen, und da auch privatrechtlich organisierte Medien zumindest nach der Rechtsordnung einzelner Länder sogar ausdrücklich eine öffentliche Aufgabe zu erfüllen haben, ${ }^{66}$ stellt sich immer mehr (auch) für den EU-Mitgliedstaat Deutschland die Frage, wie weit der nach der deutschen Verfassungsordnung länderseitig zu definierende Auftrag der Rundfunkanstalten geht und gehen darf. Daran anknüpfend steht auch die Finanzierung des öffentlich-rechtlichen Rundfunks fortdauernd auch im Blick auf ihren Daseinsvorsorge-Bezug auf dem beihilfeaufsichtsrechtlichen Prüfstand. ${ }^{67}$

64 Europäische Kommission, Mitteilung über die Anwendung der Vorschriften über staatliche Beihilfen auf den öffentlich-rechtlichen Rundfunk (2009/C 257/01), ABl. EU 2009, Nr. C 257/1, Tz. 9 f.

65 Dies hat auch das BVerfG in seinem jüngsten Rundfunkbeitrags-Urteil hervorgehoben: Es anerkannte nicht nur inzident, dass der öffentlich-rechtliche Rundfunk als „Demokratieabgabe“ der gesamten Gesellschaft nutzt und in besonderem Maße die Grundlagen der Informationsgesellschaft fördert und einen wichtigen Beitrag zur Integration und Teilhabe an demokratischen, kulturellen und wirtschaftlichen Prozessen leistet. Es betonte zugleich - auch im Blick auf die genannten Wandlungen - die individuelle Vorteilhaftigkeit der Möglichkeit, den öffentlich-rechtlichen Rundfunk zu nutzen, als Grundlage der abgabenrechtlichen Verfassungskonformität des Rundfunkbeitrags; vgl. BVerfG, Urteil des Ersten Senats vom 18. Juli 2018 - 1 BvR 1675/16 - [75-80].

66 Vgl. Badura (1996), S. 8.

67 Vgl. Frenz (2007), Rn. 484. 


\section{b) Die Altmark-Trans-Judikatur des EuGH}

Vor dem aufgezeigten unionsverfassungsrechtlichen Hintergrund wurde ein Streit über die Frage ausgetragen, wie öffentliche Finanzhilfen zum Ausgleich der Kosten der Erfüllung von Gemeinwohlverpflichtungen der Unternehmen beihilferechtlich zu beurteilen sind: als Gegenleistung für die Erfüllung der Gemeinwohlverpflichtungen und somit nicht als Beihilfe (,Tatbestandslösung“) oder als notifikationspflichtige Beihilfe, über deren Vereinbarkeit mit dem Binnenmarkt die Kommission in Anwendung der Kriterien des Art. 106 Abs. 2 AEUV zu entscheiden hätte („Rechtfertigungsmodell“). ${ }^{68}$

Der EuGH entschied sich im Urteil Altmark Trans ${ }^{69} 2003$ für die Herausnahme der Ausgleichsleistungen aus dem Beihilfebegriff, allerdings unter strengen Voraussetzungen, den folgenden sog. vier ,Altmark Trans-Kriterien“: 70

1. Betrauung: Das begünstigte Unternehmen muss tatsächlich mit der Erfüllung gemeinwirtschaftlicher Verpflichtungen betraut sein, und diese Verpflichtungen müssen klar definiert sein.

2. Transparenz: Die Parameter, anhand deren der Ausgleich berechnet wird, sind zuvor objektiv und transparent aufzustellen, um zu verhindern, dass der Ausgleich einen wirtschaftlichen Vorteil mit sich bringt, der das Unternehmen, dem er gewährt wird, gegenüber konkurrierenden Unternehmen begünstigt.

3. Erforderlichkeit: Der Ausgleich darf nicht über das hinausgehen, was erforderlich ist, um die Kosten der Erfüllung der gemeinwirtschaftlichen Verpflichtungen unter Berücksichtigung der dabei erzielten Einnahmen und eines angemessenen Gewinns aus der Erfüllung dieser Verpflichtungen ganz oder teilweise zu decken.

4. Effizienz: Wenn die Wahl des Unternehmens, das mit der Erfüllung gemeinwirtschaftlicher Verpflichtungen betraut werden soll, im konkreten Fall nicht im Rahmen eines Verfahrens zur Vergabe öffentlicher Aufträge erfolgt, das die Auswahl desjenigen Bewerbers ermöglicht, der diese Dienste zu den geringsten Kosten für die Allgemeinheit erbringen kann, so ist die Höhe des erforderlichen Ausgleichs auf der Grundlage einer Analyse der Kosten zu bestimmen, die ein durchschnittliches, gut geführtes Unternehmen, das so angemessen ausgestattet ist, dass es den gestellten gemeinwirtschaftlichen Anforderungen genügen kann, bei der Erfüllung der betreffenden Verpflichtungen hätte, wobei die dabei erzielten Einnahmen und ein angemessener Gewinn aus der Erfüllung dieser Verpflichtungen zu berücksichtigen sind.

68 Vgl. Götz, in: Dauses/Ludwigs (2019), H.III Rn. 17; Gundel, RIW 2002, 222 (225 ff.); Nettesheim, EWS 2002, 253 (258 ff.) jeweils m.w.N.

69 EuGH, Rs. C-280/00, [2003] Altmark Trans GmbH und Regierungspräsidium Magdeburg (im Anschluss an EuGH, Rs. C-53/00, [2001] Ferring).

70 Vgl. hierzu z.B. Arhold, in: Montag \& Säcker (2011), Art. 107 AEUV Rn. 222 ff.; Mestmäcker \& Schweitzer, in: Immenga\& Mestmäcker (2016), S. 82 ff.; dies. (2014), S. 999 ff.; Wernicke, in Grabitz, Hilf \& Nettesheim (2018), Art. 106 AEUV Rn. 110 ff. 
Die Europäische Kommission hat diese Kriterien aufgegriffen ${ }^{71}$ und die Gerichte der EU wenden sie in ständiger Rechtsprechung an. ${ }^{72}$ Dabei befasste sich das EuG in einer Entscheidung zum dänischen System der Finanzierung des öffentlich-rechtlichen Rundfunks zwar nicht inhaltlich mit den Ausführungen in dem Beschluss der Kommission zu den Indexierungsaspekten des dänischen Finanzierungssystems. Dieser Teil des Beschlusses wird vom EuG lediglich wegen eines aus Sicht des Gerichts fehlerhaften Verständnisses des Verhältnisses der vier Altmark-Trans-Kriterien zueinander als rechtsfehlerhaft eingestuft. ${ }^{73}$ Soweit sich die Altmark-Voraussetzungen auf eines der vier Merkmale des Begriffs der staatlichen Beihilfe im Sinne von Art. 107 Abs. 1 AEUV bezögen, und zwar auf den Vorteil für den Begünstigten, bestehe das gemeinsame Ziel aller Altmark-Voraussetzungen darin, zu prüfen, ob der Ausgleich, der einem Unternehmen für die Durchführung eines öffentlichrechtlichen Auftrags gewährt wird, einen wirtschaftlichen Vorteil darstellt, der das Unternehmen, dem er gewährt wird, gegenüber konkurrierenden Unternehmen begünstigt. Doch auch wenn alle Altmark-Voraussetzungen durch dieses gemeinsame Ziel miteinander verbunden seien, komme jeder von ihnen eine eigenständige und von den anderen Voraussetzungen unabhängige Funktion zu.

Die zweite Altmark-Voraussetzung beinhalte drei Anforderungen, denen die Parameter für die Berechnung des Ausgleichs genügen müssten, damit gewährleistet sei, dass die Berechnung zuverlässig ist und von der Kommission überprüft werden kann. Keineswegs gehe aus dem Urteil Altmark hervor, dass nach der dort aufgestellten zweiten Voraussetzung die Parameter für die Berechnung des Ausgleichs so formuliert werden müssen, dass die Höhe der Ausgaben des Ausgleichsempfängers beeinflusst oder kontrolliert werden kann.

Eine Auslegung der zweiten Altmark-Voraussetzung dahingehend, dass die Parameter für die Berechnung des Ausgleichs nicht nur objektiv und im Voraus im Rahmen eines transparenten Verfahrens festzulegen sind, sondern darüber hinaus auch die Effizienz der Durchführung des öffentlich-rechtlichen Auftrags gewährleisten müssen, sei mit dem Wortlaut der zweiten Altmark-Voraussetzung nicht vereinbar und führe zu einer Vermengung der vorliegend untersuchten Voraussetzung mit der vierten Altmark-Voraussetzung.

Aus dieser Entscheidung folgt zwar einerseits inzident, dass der EuG Methoden einer Indexierung im System der Finanzierung des öffentlich-rechtlichen Rundfunks nicht per se als beihilfeaufsichtsrechtlich bedenklich einstuft. Ebenso wenig stuft er allerdings auch die kritische Haltung der Europäischen Kommission gegenüber solchen Indexierungsansätzen

71 Vgl. Europäische Kommission, Mitteilung über die Anwendung der Beihilfevorschriften der EU auf Ausgleichsleistungen für die Erbringung von Dienstleistungen von allgemeinem wirtschaftlichen Interesse, ABl. EU 2012 Nr. C 8/4, Tz. 420.

72 Vgl. z.B. EuGH, Rs. C-451/03 [2006] Servizi Ausilian Dottori Commercialisti [62, 64, 66-67]; Rs. C-206/06 [2007] Essent Networks Noord u.a. [81-85]; Rs. C-140/09, [2010] Fallimento Traghetti del Mediterraneo, [36-40]; Rs. C 399/08 P, [2010] Kommission/Deutsche Post, [39-43]; EuG, Rs. T-366/13, [2017] SNCM, [44-48]; Rs. T-202/10 RENV II u. T-203/10 [2018] RENV II u. Stichting Woonlinie u.a., [73-82].

73 EuG, Rs. T-674/11 [2015] TV2/Danmark/Kommission [94-106]. 
als per se rechtsfehlerhaft ein. Für die Frage, ob eine solche kritische Kommissions-Haltung in der Beihilfeaufsichtspraxis einer gerichtlichen Überprüfung standhält, kommt es darauf an, an welcher Stelle des Altmark-Trans-Prüfungsschemas sie eingebunden wird. Einer Einbindung einer kritischen Haltung der Europäischen Kommission zu Indexierungsansätzen im Rahmen des dritten und/oder vierten Altmark-Trans-Kriteriums steht die Entscheidung des EuG nicht entgegen.

In der Entscheidung anerkannte das EuG zudem zwar, dass die Anwendung des vierten Altmark-Trans-Kriteriums, des Effizienz-Kriteriums, praktische Schwierigkeiten bereiten könne, wenn das Unternehmen, dem die Durchführung eines öffentlich-rechtlichen Auftrags übertragen worden sei, nicht im Rahmen eines Verfahrens zur Vergabe öffentlicher Aufträge ausgewählt wurde - wie dies auch in Deutschland der Fall ist: Der Begriff eines „gut geführten und angemessen ausgestatteten Unternehmens“ gehe zwangsläufig mit einem weiten Ermessensspielraum der Stelle, die ihn anwende, einher. Zudem falle es schwer, zwei Unternehmen, von denen eines staatlich und mit einem öffentlich-rechtlichen Auftrag betraut ist, während das andere privat und nicht durch einen solchen Auftrag gebunden ist, miteinander zu vergleichen, weil $u$. a. das Unternehmen, das mit dem öffentlichrechtlichen Auftrag betraut ist, bestimmten Qualitätsanforderungen unterliege. Wenn kein Verfahren zur Vergabe öffentlicher Aufträge, das die Auswahl desjenigen Bewerbers ermöglicht, der den öffentlich-rechtlichen Auftrag zu den geringsten Kosten durchführen kann, stattgefunden habe, sei allerdings - so der EuG - dennoch der zu gewährende Ausgleich durch Bezugnahme auf ein durchschnittliches, gut geführtes und mit den erforderlichen Mitteln angemessen ausgestattetes Unternehmen festzulegen. Die Suche nach einem solchen Unternehmen diene dazu, die Höhe des Ausgleichs, der für die Durchführung des öffentlich-rechtlichen Auftrags als erforderlich angesehen wird, zu optimieren und zu vermeiden, dass die höheren Kosten eines ineffizienten Unternehmens als Bezugsgröße in die Berechnung der Höhe des Ausgleichs einfließen. Werde nämlich keine Optimierung der Höhe des Ausgleichs vorgenommen, könne nicht ausgeschlossen werden, dass der Ausgleich einen wirtschaftlichen Vorteil mit sich bringe, der das Unternehmen, dem er gewährt werde, gegenüber konkurrierenden Unternehmen begünstige.

Um dem vierten Kriterium zu genügen, reiche es nicht aus, dass der Mitgliedstaat erklärt, angesichts der Besonderheiten des öffentlich-rechtlichen Auftrags sei es nicht möglich, auf dem Markt ein Unternehmen zu finden, das dem Ausgleichsempfänger vergleichbar sei, und sich anschließend um den Nachweis bemüht, dass der Begünstigte selbst ein „gut geführtes und angemessen ausgestattetes Unternehmen“ im Sinne dieser Voraussetzung ist. Jedenfalls sei im Bereich des Rundfunks auch unter Berücksichtigung der gemeinwirtschaftlichen Verpflichtungen öffentlich-rechtlicher Rundfunkanstalten ein großer Teil der Ausgaben privater Rundfunkunternehmen und öffentlich-rechtlicher Rundfunkanstalten im Wesentlichen ähnlich und vergleichbar. Sowohl private als auch öffentliche Rundfunkbetreiber hätten nämlich die Kosten geistiger Eigentumsrechte, Produktions- und Koproduktionskosten, Ausgaben für den Einkauf von Waren und Dienstleistungen in Verbindung mit der Entwicklung von Produkten und Projekten sowie Personalkosten zu tragen. Außer- 
dem unterscheide sich ein Teil des Programms und der Produktion öffentlich-rechtlicher Rundfunkanstalten nicht wesentlich vom Angebot der privaten Unternehmen, so dass ein Kostenvergleich zumindest in einem gewissen Umfang möglich sei. In diesem Umfang muss der Kostenvergleich dann auch erfolgen. ${ }^{74}$

$\mathrm{Da}$ es sich bei dem Kostenvergleich um eine fortdauernde Angelegenheit handelt, die nicht mit dem Moment der Auftragsbestimmung und -vergabe abgeschlossen ist, kommt diesem Kostenvergleich auch bei einem Vollindexierungsmodell besondere Bedeutung zu.

Auch die Aufhebung der Entscheidung des EuG im Rechtsmittelverfahren, ${ }^{75}$ die wegen dessen zu engem Verständnis des Beihilfe-Begriffs des Art. 107 Abs. 1 AEUV erfolgte, hindert die Europäische Kommission nicht an einer fortdauernd kritischen Haltung zu Ansätzen einer Vollindexierung im System der Finanzierung des öffentlich-rechtlichen Rundfunks.

Die Rechtsprechung der Gerichte der EU lässt im Ergebnis noch Raum für die Anwendung der Beihilfenaufsicht in Fällen, in denen nicht sämtliche vier Altmark-Trans-Kriterien für Ausgleichsleistungen, die aus dem Beihilfebegriff herausfallen, erfüllt sind. ${ }^{76}$

\section{Zur Bedeutung der kulturpolitischen Querschnittsklausel}

Die kulturpolitische Querschnittsklausel in Art. 167 Abs. 4 AEUV ist zwar auch mit Blick auf das kulturelle Substrat der Medien bedeutsam. Dies klingt in der Bezugnahme auf den „audiovisuellen Bereich“ in Art. 167 Abs. 2 AEUV unmittelbar an. Art. 167 Abs. 4 AEUV kommt indessen in der bisherigen Beihilfeaufsichtspraxis der Europäischen Kommission wie auch der diesbezüglichen Judikatur der Gerichte der EU nur eine marginale Bedeutung zu. Die Norm wird zwar in der Aufsichts- und Spruchpraxis erwähnt, in ihrer juristischen Steuerungsfunktion allerdings kaum über transparente Abwägungsprozesse effektuiert.

Dies befremdet deshalb, weil die Regelung ungeachtet ihrer feststellenden Formulierung ,trägt ... Rechnung“ für die Organe der EU die rechtlich bindende, nicht lediglich politisch-appellative Verpflichtung enthält, bei allen ihren Tätigkeiten im Rahmen des AEUV, d.h. auch bei der Beihilfeaufsicht im Blick auf Finanzierungssysteme für öffentlich-rechtliche Rundfunkveranstalter, kulturelle Aspekte zu berücksichtigen. ${ }^{77}$ Dieses Gebot der Rücksichtnahme ist ein spezifischer Ausdruck des in Art. 4 Abs. 3 EUV verankerten Grundsatzes der Unionstreue, die eine schonende, die widerstreitenden Interessen möglichst optimal ausgleichende Interpretation der Kompetenztitel verlangt. ${ }^{78}$ Zielkonflikte zwischen der

74 EuG Rs. T-674/11 [2015] TV 2/Danmark/Kommission [114-119].

75 EuGH, Rs. C-657/15 P [2017] Viasat Broadcasting UK/TV2/Danmark [35-56].

76 Vgl. Götz, in: Dauses \& Ludwigs (2019), H.III Rn. 17.

77 Vgl. Bellucci, ELJ 2010, 211 (212 f.); Psychogiopoulou (2008), S. 56 ff.; Schwartz, AfP 1993, 409 (417); Wemmer (1996), S. 117; a.A. Berggreen-Merkel (1995), S 19 f.: Lane, CMLR 1993, 939 (978).

78 Vgl. Eberle (1993), S. 948 f.; Lichtenegger (2014), S. 356 ff. 
Wahrung und Förderung der Kultur, auch im audiovisuellen Bereich, und dem Ziel der Wahrung der Wettbewerbsordnung innerhalb der EU sind zwar bei der unionalen Beihilfeaufsicht gegenüber öffentlich-rechtlicher Rundfunkfinanzierung weder a priori im Zweifel für ${ }^{79}$ noch stets im Zweifel gegen die kulturbezogene Finanzierungssouveränität der Mitgliedstaaten zu lösen. ${ }^{80}$ Indessen wird den Mitgliedstaaten über Art. 167 Abs. 4 AEUV ein kultur- und insoweit auch medienpolitischer „Freiraum“ zugestanden, den die Organe der EU unangetastet lassen müssen und auf den sie daher nicht durch Rechtsetzung, Rechtsanwendung oder Rechtsprechung beschränkend einwirken dürfen. Demzufolge können Maßnahmen nationaler Medienpolitik selbst dann bei europarechtsdogmatischer Betrachtung in bestimmten Fällen zulässig sein, wenn sie an sich im Widerspruch zu Einzelbestimmungen des AEUV, wie z.B. dessen Beihilfeaufsichtsregime, stehen oder zu stehen scheinen. ${ }^{81}$

Der Querschnittsklausel kommt danach - ebenso wie (a) den in Art. 2 EUV verankerten Grundwerten der Demokratie und des Pluralismus ${ }^{82}$ und (b) dem in Art. 4 Abs. 2 Satz 1 EUV normierten Gebot der Wahrung der nationalen Identität der Mitgliedstaaten nach Art. 4 Abs. 2 Satz 1 EUV $^{83}$ - Bedeutung bei der Wahrnehmung der Kontrollbefugnisse der Unionsorgane gegenüber mitgliedstaatlichem Verhalten $\mathrm{zu}^{84}$ Und diese auslegungsleitende Bedeutung des Art. 167 Abs. 4 AEUV bei der Wahrnehmung von Kontrollkompetenzen erkennt die Kommission nicht zuletzt auch bei der Prüfung der Unionsrechtskonformität der Finanzierung öffentlich-rechtlichen Rundfunks in den Mitgliedstaaten im Ausgangspunkt auch an. ${ }^{85}$ Nicht nur im Bereich der rundfunkfinanzierungsbezogenen Beihilfeaufsicht fehlt es bei der wettbewerbsrechtlichen Kontrolltätigkeit indessen an einem nachvollziehbaren Subsumptionsprozess. ${ }^{86}$

79 So im Ansatz mit Bezug auf einen Vorrang der Vorbehaltsrechte der Mitgliedstaaten der EU in Bezug auf die Kultur gegenüber den wirtschaftlichen Geboten des Binnenmarktes Rabe (2006), S. 177; Schwarze, ZUM 2003, 15 (21 f.).

80 Vgl. Ress \& Ukrow, in: Grabitz, Hilf \& Nettesheim (2018), Art. 167 AEUV Rn. 154.

81 Vgl. Ress (1991), S. 51.

82 Vgl. zu diesen Grundwerten und ihrer Anwendungsrelevanz z.B. Korte (2016), S. 167 ff.; Müller (2014), S. $153 \mathrm{ff}$.

83 Vgl. hierzu z.B. Jungheim (2012), S. 195; Wendel (2011), S. 572 ff.

84 Vgl. hierzu z.B. auch Entschließung des Rates v. 12.2.2001 zu den einzelstaatlichen Beihilfen für die Filmwirtschaft und den audiovisuellen Sektor, ABl. C 73, 3, Tz. 1.

Bedeutsam ist insoweit insbesondere die Demokratie- und Vielfaltsrelevanz von Auftrag und Finanzierung des öffentlich-rechtlichen Rundfunks.

85 Vgl. Kommission der EG (2001), Tz. 26.

86 So hat die Europäische Kommission zwar auch in ihrer CISAC-Entscheidung v. 16.7.2008 (COMP/C 2/38.698, Rn. 93 ff.) bei der Darstellung des rechtlichen und politischen Kontext ihrer Untersagungsverfügung auf die Querschnittsklausel hingewiesen. Diese Aufsichtsmaßnahme bezog sich auf einen Mustervertrag für Gegenseitigkeitsvereinbarungen der CISAC, der Dachorganisation der Verwertungsgesellschaften, soweit dieser Mustervertrag Beschränkungen der Mitgliedschaft und territoriale Beschränkungen enthielt. Eine differenzierte Auseinandersetzung mit der Bedeutung der Querschnittsklausel, namentlich in Form einer Subsumption der Tatbestandsmerk- 
Auch in der bisherigen Judikatur des EuGH ist die souveränitätsschonende Funktion der Klausel nicht (nachvollziehbar) rezipiert: Wo sich der EuGH bislang (sehr vereinzelt) mit der Querschnittsklausel befasste, geschah dies vielmehr in einer das Tätigwerden der EU absichernden Weise: So kann nach dessen Judikatur Art. 167 AEUV z.B. nicht als unionsrechtlicher Rechtfertigungsgrund für nationale Maßnahmen auf dem Gebiet der Kultur, die den innergemeinschaftlichen Handel behindern können, geltend gemacht werden. ${ }^{87}$

Das Unionsrecht ist mithin zwar „im Lichte des Art. 167 Abs. 4 AEUV“ auszulegen. Ob die Organe der EU allerdings dieser Auslegungsmaxime genügen, lässt sich auf Basis der bisherigen Rechtsanwendung nicht angemessen beurteilen. Ein bloßes Zitat einer Norm ersetzt nicht deren Operationalisierung. Dass Kommission oder Gerichte der EU in einen entsprechenden Abwägungsprozess eintreten, ist den Entscheidungen dieser Organe bislang nicht zu entnehmen. Die kulturpolitische Querschnittsklausel teilt insoweit das Schicksal des Subsidiaritätsprinzips: Ein mitgliedstaatliche Souveränität schonendes Instrument des Unionsrechts fristet ein Schattendasein. In Bezug auf die kulturpolitische Querschnittsklausel fehlt es zudem bislang an einer verfahrensrechtlichen Absicherung, wie sie für das Subsidiaritätsprinzip durch die Subsidiaritätsrüge nach Art. 6 des Protokolls über die Anwendung der Grundsätze der Subsidiarität und der Verhältnismäßigkeit vom 13.12.2007 ${ }^{88}$ eingeführt worden ist.

Vor diesem Hintergrund spricht bereits im Lichte der bisherigen Praxis wenig dafür, dass die kulturpolitische Querschnittsklausel einer beihilfeaufsichtsrechtlichen Kontrolle des Übergangs zu einer Vollindexierung der Fortentwicklung der Höhe des Rundfunkbeitrages merkliche Grenzen setzen wird. Aber jenseits dieser praktischen Erfahrungswerte lassen auch rechtsdogmatische Erwägungen die aufsichtsbegrenzende Wirkung der Klausel beschränkt erscheinen.

Insoweit ist zunächst zu berücksichtigen, dass der Grundsatz des Art. 167 Abs. 4 AEUV eine Ausnahme gegenüber den allgemeinen Regeln des AEUV darstellt und daher restriktiv auszulegen ist. Dementsprechend sind nationale kulturelle, einschließlich medien- und insbesondere rundfunkfinanzierungsrechtlicher Sonderregeln nur insoweit vom Anwendungsbereich der Vertragsbestimmungen ausgenommen, als ihr Zweck dies erfordert. ${ }^{89}$ Aus diesem Grund ist eine Voraussetzung für die souveränitätsschonende Wirkung des Art. 167 Abs. 4 AEUV, dass mit einer nationalen Regelung ein ausschließlich kulturpolitischer Zweck verfolgt wird. ${ }^{90}$

male der Klausel in Bezug auf die konkreten kartellrechtlichen Fragestellungen findet allerdings nicht statt; vgl. hierzu auch Breuer (2013), S. $412 \mathrm{ff}$.

87 EuGH, Rs. C-531/07 [2009] Fachverband der Buch- und Medienwirtschaft [33]. Vgl. zur bisher geringen praktischen Relevanz der Querschnittsklausel in der Rechtsprechung bereits zuvor von Danwitz, NJW 2005, 529 (533).

88 ABl. EU 2007Nr. C 306 S. 150.

89 Vgl. de Witte (1995), 229 (255 ff.); Ress \& Ukrow, in: Grabitz, Hilf \& Nettesheim (2018), Art. 167 AEUV Rn. 154.

90 Vgl. Ress \& Ukrow, in: Grabitz, Hilf \& Nettesheim (2018), Art. 167 AEUV Rn. 154. 
Ob das Interesse an einer lediglich moderaten, wenn auch nachhaltig moderaten Erhöhung der den öffentlich-rechtlichen Rundfunkanstalten zur Verfügung stehenden Mitteln eine solche ausschließlich kulturpolitische Zwecksetzung darstellt, erscheint ebenso offen wie die Einordnung des Interesses an einer „Entpolitisierung“91 i.S. der Vermeidung regelmäßiger parlamentarischer und gesellschaftlicher Debatten über eine Erhöhung des Rundfunkbeitrages im Lichte dieses Ausschließlichkeitskriteriums.

Denn Kultur lebt ebenso wie Demokratie von Offenheit, von Diskurs und Transparenz. Hintergrund für populistische Bewegungen in Europa, die immer wieder auch öffentlichrechtliche Medien ins Zentrum ihrer Kritik nehmen, ist vielfach auch der Vorwurf einer Verzerrung demokratischer Prozesse und kultureller Autonomie.

Hintergrund dafür ist auch eine Ablehnung des kulturellen Leitbildes des Art. 167 AEUV in seiner spezifischen Verbindung von Wahrung kulturellen Erbes und Förderung von und Offenheit für kulturelle Vielfalt. In den allgemeinen Programmgrundsätzen des RStV und der parallelen Regelungen für die ARD-Anstalten und das ZDF findet dieses Kulturkonzept der Toleranz und Verständigungsbereitschaft ein spezifisch medienrechtliches Pendant. Verständigungsbereitschaft kann indessen weder national noch europäisch und international als immerwährend vorausgesetzt werden; vielmehr bedarf sie der steten Bestätigung und Bekräftigung in einem fortdauernden gesellschaftlichen und politischen Diskurs. Da der seit dem Ende des Zweiten Weltkrieges zwar nie vollständig unumstrittene, aber doch die Entwicklung maßgeblich prägende Konsens zu den Werten einer westlichen, freien und demokratischen Welt zunehmend transatlantisch in Frage gestellt wird, bedarf es auch medial einer kritischen Reflexion der politischen, ökonomischen, sozialen und kulturellen Veränderungs- und Erosionsprozesse, die die Kritik an den Werten des Art. 2 EUV und deren praktischer Relevanz und Beachtung wachsen lassen. ARD und ZDF können insoweit aber nur dann glaubwürdiges Medium einer solchen kulturellen Debatte sein, wenn sie auch in ihrer Rolle als Faktor und Gegenstand dieser Debatte anerkannt werden. Ein Bemühen, Aufgabe und Funktion des öffentlich-rechtlichen Rundfunks als Grundlage ihres Finanzgewährleistungsanspruchs aus dem gesellschaftlichen und politischen Diskurs auszugrenzen, hieße an dieser Stelle, die kulturelle Dimension des öffentlich-rechtlichen Rundfunks in ihrer demokratisch-partizipativen Ausformung nicht zu stärken, sondern zu schwächen.

Die Anerkennung der demokratischen und gesellschaftlichen Relevanz des öffentlichrechtlichen Rundfunks im Amsterdamer Protokoll,92 die dieses kulturell-demokratische Verständnis aufgreift, spricht bei einer Risikobewertung tendenziell gegen eine kulturpoliti-

91 Vgl. hierzu Cornils (2019), S. 4 f.; Hoffmann-Riem 1991), S.201; Nickel, ZUM 2006, 737 (738 ff.).

92 Vgl. hierzu Abschnitt V.

Der europarechtliche Begriff des öffentlich-rechtlichen Rundfunks ist im Übrigen autonom zu interpretieren, wobei mitgliedstaatliches Begriffsverständnis diese Auslegung allerdings mitbestimmen kann. Europarechtlich werden vom Begriff nicht per se ausschließlich Veranstalter in öffentlich-rechtlicher Organisatinsform erfasst; auch privatrechtlich verfasste Anbieter, die öffentliche 
sche Absicherung eines „Entpolitisierungs“-Interesses in Bezug auf Aufgaben, Funktion und damit verbundene Finanzierung des öffentlich-rechtlichen Rundfunks.

Voraussetzung für die Wirkung der Querschnittsklausel in Richtung auf kultur- und medienpolitische Freiräume eines Mitgliedstaates ist zudem, dass dieser Freiraum i.S. einer kultur- und medienordnungsrechtlichen Kohärenz genutzt wird: Dies setzt „das konzeptionelle Aufeinander-Bezogen-Sein von Rechtssätzen und Realakten“ kultur- und medienrechtlich agierender Mitgliedstaaten voraus. ${ }^{93}$ Auch wenn der EuGH die Anforderung einer „kohärenten und systematischen“ Regelung besonders im Glückspielrecht entwickelt hat, ${ }^{94}$ ist die rechtsdogmatische Bedeutung des Kohärenzkriteriums i.S. eines Gebots der Wertungskohärenz dennoch nicht auf den Glücksspielbereich begrenzt. ${ }^{95}$ Diesem Kriterium kommt vielmehr Auslegungsrelevanz in allen Bereichen zu, in denen aufgrund der Kompetenzverteilung zwischen der EU und ihren Mitgliedstaaten weite Beurteilungsspielräume bei den Mitgliedstaaten verbleiben - wie dies bei Aufgaben, Struktur und Finanzierung des öffentlich-rechtlichen Rundfunks ungeachtet der Harmonisierungswirkung der AVMDRichtlinie im audiovisuellen Bereich weiterhin der Fall ist. Die kultur- und medienrechtliche Kohärenz fordert die Stringenz und Stimmigkeit verschiedener kultur- und medienrechtlicher Maßnahmen zueinander sowie das Fehlen von Widersprüchen zwischen diesen Maßnahmen gemessen an einem gemeinsamen kultur- und medienrechtlichen Ziel. Das medienrechtliche (Schutz-)Ziel als Prüfungsmaßstab des medienrechtlichen Kohärenzgebotes wird durch den Mitgliedstaat selbst bestimmt; an diesem Ziel muss sich der Mitgliedstaat dann allerdings in seinem staatlichen Verhalten von exekutiver, legislativer und judikativer Gewalt auch messen lassen. ${ }^{96} \mathrm{Ob}$ das Ziel einer funktionsgerechten Finanzausstattung des öffentlich-rechtlichen Rundfunks mit dem Übergang zu einer „Vollindexierung“ kohärenzkonform in Deckung zu bringen ist, erscheint zumindest dann nicht per se gesichert, wenn dieser Übergang

- den demokratischen Diskurs über diese Finanzausstattung weniger als Chance denn als Gefahr wahrzunehmen und

- verfahrensrechtliche Instrumente, die die Bedarfsgerechtigkeit absichern, in ihrer Bedeutung zu minimieren

scheint.

Zuschüsse für die Erfüllung besonderer Aufträge erhalten, können als sog. public service broadcasters eingestuft werden; vgl. dazu Cole/Oster (2017), S. 27.

93 Schorkopf, in: Grabitz, Hilf \& Nettesheim (2018), Art. 7 AEUV Rn. 11.

94 Vgl. insbesondere EuGH, Rs. C-243/01, [2003] Gambelli [67] Slg. 2003, I-13031 Rn. 67 ff.; Rs. C-338/04 [2007] Placanica [53]; Rs. C-169/07 [2009] Hartlauer [55] Vgl. hierzu z.B. Hartmann, EuZW 2014, 814 (815f.); Lippert, EuR 2012, 90 (95); Michl, ZfWG 2016, 110 (111); Streinz, ZfWG 2013, 305 (306 ff.).

95 Vgl. Dieterich (2014), S. 741 ff.; Schuster (2017), S. 79 ff.

96 Vgl. Frenz, EuR 2012, 344 (348 f.). 


\section{Zur Bedeutung des Amsterdamer Protokolls über den öffentlich- rechtlichen Rundfunk}

Mit dem (durch den Vertrag von Amsterdam eingefügten und durch den Vertrag von Lissabon redaktionell angepassten) Protokoll über den öffentlich-rechtlichen Rundfunk in den Mitgliedstaaten ${ }^{97}$ wird der besonderen Funktion des öffentlich-rechtlichen Rundfunks in den Mitgliedstaaten Rechnung getragen, was im Erwägungsgrund des Protokolls zum Ausdruck kommt: Die Regelung erfolgt „(i)n der Erwägung, dass der öffentlich-rechtliche Rundfunk in den Mitgliedstaaten unmittelbar mit den demokratischen, sozialen und kulturellen Bedürfnissen jeder Gesellschaft sowie mit dem Erfordernis verknüpft ist, den Pluralismus in den Medien zu wahren“".

Auf der Grundlage und im Rahmen dieser Funktion berühren die Bestimmungen der Verträge, d.h. des EUV und des AEUV, nach dem Protokoll, das gemäß Art. 51 EUV primärrechtlich die Anwendung und Auslegung des Unionsrechts mitbestimmt, ,nicht die Befugnis der Mitgliedstaaten, den öffentlich-rechtlichen Rundfunk zu finanzieren, sofern die Finanzierung der Rundfunkanstalten dem öffentlich-rechtlichen Auftrag, wie er von den Mitgliedstaaten den Anstalten übertragen, festgelegt und ausgestaltet wird, dient".

Mit Blick auf die Frage, was von der Auftragsdefinition mit Blick auf den vorgenannten Erwägungsgrund des Protokolls erfasst sein muss, verfügen die Mitgliedstaaten über eine Einschätzungsprärogative. ${ }^{98}$ Allerdings erfasst dieser Gestaltungsspielraum der Mitgliedstaaten nur das „wie“ des Inhalts, nicht das „ob“ der Existenz einer Auftragsgestaltung. Bei dieser Auftragsgestaltung muss es sich im Kern zudem um eine hoheitlich geformte Ausgestaltung handeln; eine Auftragsdefinition, die dem öffentlich-rechtliche Rundfunk selbst umfassend oder im Schwerpunkt überlassen bliebe, wäre tatbestandlich nicht vom Amsterdamer Protokoll erfasst.

Außerdem dürfen die Handels- und Wettbewerbsbedingungen in der Union nicht in einem Ausmaß beeinträchtigt werden, das dem gemeinsamen Interesse zuwiderläuft, wobei den Erfordernissen der Erfüllung des öffentlich-rechtlichen Auftrags Rechnung zu tragen ist. Es stellt eine dem Rücksichtnahmegebot entsprechende Einschränkung der beihilfeaufsichtsrechtlichen Kontrolle dar, dass diese Schrankensetzung die Finanzierung des Auftrags, nicht die Finanzierung des öffentlich-rechtlichen Rundfunks als solche betrifft. ${ }^{99}$

Auch das gemeinsame Interesse i.S. dieses Protokolls ist bei der unionsrechtlichen Kontrolle der Finanzierung des öffentlich-rechtlichen Rundfunks in den Mitgliedstaaten nicht nur aus den im Protokoll angesprochenen Erfordernissen der Erfüllung des öffentlichrechtlichen Auftrags, sondern auch aus Art. 167 Abs. 1 (Erhaltung der nationalen Kulturen der Mitgliedstaaten unter Wahrung ihrer nationalen und regionalen Vielfalt und Hervorhe-

97 Vgl. zum Protokoll z.B. Ferreau (2017), S. 28 ff.; Jungheim (2012), S. 201 ff.; Stulz-Herrnstadt (2004), S. $280 \mathrm{ff}$.

98 Vgl. Ferreau (2017), S. 29; Schladebach \& Simantiras, EuR 2011, 784 (788).

99 Vgl. zu dieser Begrenzung Ferreau (2017), S. 29. 
bung des gemeinsamen kulturellen Erbes) sowie Art. 167 Abs. 4 AEUV zu definieren. Denn der öffentlich-rechtliche Rundfunk hat, wie auch die Europäische Kommission anerkennt, ${ }^{100}$ eine wichtige Rolle bei der Förderung der kulturellen Vielfalt jedes Mitgliedstaates zu spielen, indem er nicht zuletzt Bildung und Erziehung gewidmete Programme anbietet, die Öffentlichkeit auf zuverlässige und in quantitativ bedeutsamer Weise informiert, die Meinungsvielfalt sichert und (jenseits einer Gebührenfinanzierung) ohne zusätzliches Entgelt qualitativ hochwertige Unterhaltung anbietet.

\section{Zur Bedeutung der Mitteilung der Kommission über die Anwendung der Vorschriften über staatliche Beihilfen auf den öffentlich-rechtlichen Rundfunk}

\section{Einführung}

Die Mitteilung der Europäischen Kommission aus 2009 über die Anwendung der Vorschriften über staatliche Beihilfen auf den öffentlich-rechtlichen Rundfunk ${ }^{101}$ prägt seither die Ausübung der Beihilfenaufsicht über die Finanzierung des öffentlich-rechtlichen Rundfunks. Sie widmet sich der Beihilfeneigenschaft der Finanzierung, der Art der Beihilfe (bestehende oder neue Beihilfe) und der Vereinbarkeit der Beihilfe mit dem Binnenmarkt.

Die Mitteilung geht von der Vermutung einer Beihilfequalität der Finanzierung des öffentlich-rechtlichen Rundfunks aus. Es geht mithin aus Sicht der Kommission bei ihrer Aufsichtstätigkeit weniger um das „Ob“ des Bestehens als um das „Wie“ der Ausgestaltung der Beihilfe. Dieses Vorverständnis prägt auch die Aufsichtspraxis der Kommission: Sie ist bisher noch in keinem der von ihr geprüften Fälle zu dem Ergebnis gelangt ist, dass alle vier sog. Altmark-Trans-Voraussetzungen für das Verneinen einer Beihilfe-Eigenschaft erfüllt waren. ${ }^{102}$ Dies verengt zwar das Kontrollprogramm der Kommission in einer unionsrechtlich bedenklichen Weise, indessen hat diese Verengung bislang noch keine durchgreifende judikative Kritik erfahren. Allerdings hat der EuG im Fall TV 2/Danmark die Ausführungen der Kommission zu den Altmark-Trans Kriterien als unzureichend angesehen und eine Verletzung der Prüfpflicht der Kommission angenommen. ${ }^{103}$

Vor diesem Hintergrund mögen Bemühungen, die Beihilfequalität der Beitragsfinanzierung als solche im Zusammenhang mit einem Wechsel zu einem System der Vollindexierung in Frage zu stellen, zwar rechtsdogmatisch erwägenswert sein, dürften indessen rechts-

100 Vgl. Europäische Kommission (2007), Tz. 11. Vgl. zur Bedeutung des öffentlich-rechtlichen Rundfunks auch die Entschließung des Rates und der im Rat vereinigten Vertreter der Regierungen der Mitgliedstaaten v. 25.1.1999 über den öffentlich-rechtlichen Rundfunk, ABl. 1999 Nr. C 30/1; hierzu Ferreau (2017), S. $30 \mathrm{ff}$.

101 ABl. EU 2009 Nr. C 257/1.

102 Bartosch (2016), S. 340.

103 EuG, Rs. T-309/04, T-317/04, T-329/04 und T-336/04 [2008] TV 2/Danmark/Kornmission [155-168, 178-233]. 
praktisch im Hinblick auf die gefestigte Aufsichtspraxis der Europäischen Kommission ohne hinreichende Aussicht auf Erfolg sein.

Die Art der Beihilfe (bestehende oder neue Beihilfe) hat Bedeutung für das Beihilfeaufsichtsverfahren. Denn für bestehende Beihilfen erfolgt die Überprüfung nicht - wie bei neuen Beihilfen - in einem Genehmigungsverfahren, sondern in einem kooperativen Verfahren mit dem Ziel einer einvernehmlichen Regelung. ${ }^{104}$ Die Frage, ob ein Übergang zu einer Vollindexierung Bestandsschutz genießt, ist mithin von zumindest prozeduraler Bedeutung. Die Stellung des Mitgliedsstaates bei der Wahrung seiner rundfunkordnungsrechtlichen Prärogative vor Ingerenz der Kommission ist im Bereich der bestehenden Beihilfen deutlich stärker ausgeprägt.

Die Kommission erkennt in der Mitteilung ${ }^{105}$ an, dass die Finanzierungsregelungen, die derzeit in den meisten Mitgliedstaaten bestehen, bereits „,vor langer Zeit” eingeführt wurden, und zieht daraus die Schlussfolgerung, dass die Finanzierungsregelungen nach einer genaueren Einzelfallprüfung als bestehende Beihilfen i.S. des Art. 108 Abs. 1 AEUV eingeordnet werden können. Voraussetzung für eine fortdauernde Anerkennung als bestehende Beihilfe ist im Falle von nachfolgenden Änderungen in der Finanzierung, dass die späteren Änderungen die ursprüngliche Regelung nicht in ihrem Kern betreffen, sondern eher formaler und verwaltungstechnischer Art sind; im Falle wesentlicher Änderungen kommt es darauf an, ob sie für sich getrennt beurteilt werden können oder die Finanzierungsregelung insgesamt zu einer neuen Beihilfe machen. ${ }^{106}$

Der Schwerpunkt der Mitteilung liegt auf den Ausführungen zur Vereinbarkeit einer Beihilfe in Form der Finanzierung des öffentlich-rechtlichen Rundfunks mit dem Unionsrecht. Die Kommission erwartet von den Mitgliedstaaten, dass sie sich in Bezug auf die Definition des öffentlich-rechtlichen Auftrages, Betrauung und Kontrolle, Transparenz, Vermeidung von Überkompensierung, Verhältnismäßigkeit und Marktverhalten an den von ihr aufgestellten Kriterien ausrichten. ${ }^{107}$ Der betreffende Katalog orientiert sich an den Altmark-Trans-Kriterien, greift Anknüpfungspunkte des Regimes der Beihilfeaufsicht in Art. 106 Abs. 2 AEUV auf und trägt dabei dem Amsterdamer Protokoll Rechnung.

\section{Die Kriterien der Mitteilung, die Überlegungen zur Fortentwicklung des Auftrages und der Übergang zu einer Vollindexierung der Finanzierung}

Die Mitteilung greift die ständige Rechtsprechung des EuGH auf, der klarstellt, dass eine Maßnahme nur dann unter die Ausnahmeregelung des Art. 106 Abs. 2 AEUV fällt, wenn alle nachstehend genannten Voraussetzungen erfüllt sind:108

104 Götz, in: Dauses \& Ludwigs (2019), H.III Rn. 147.

105 ABl. EU 2009 Nr. C 257/1, Tz. 25.

106 A.a.O., Tz. $29 \mathrm{ff}$.

107 Vgl. Bartosch (2016), S. $340 \mathrm{ff}$.

108 Vgl. hierzu Europäische Kommission (2009), Tz. 37. 
1. Die betreffende Dienstleistung muss eine Dienstleistung von allgemeinem wirtschaftlichem Interesse und von dem Mitgliedstaat klar als solche definiert worden sein (Definition).

2. Das betreffende Unternehmen muss von dem Mitgliedstaat ausdrücklich mit der Erbringung dieser Dienstleistung betraut worden sein (Betrauung).

3. Die Anwendung der Wettbewerbsregeln des AEUV (in diesem Fall des Beihilfenverbots) muss die Erfüllung der dem Unternehmen übertragenen besonderen Aufgaben verhindern und die Freistellung von diesen Vorschriften darf die Entwicklung des Handels nicht in einem Ausmaß beeinträchtigen, das dem Interesse der EU zuwiderläuft (Verhältnismäßigkeit).

\section{a) Definition des öffentlich-rechtlichen Auftrags}

Im Hinblick auf die Erfüllung des Definitionserfordernisses für die Anwendung von Art. 106 Abs. 2 AEUV ist eine förmliche Definition des öffentlich-rechtlichen Auftrags erforderlich, die „so genau wie möglich“ erfolgen sollte. „Aus der Definition sollte unmissverständlich hervorgehen, ob der Mitgliedstaat eine bestimmte Tätigkeit des betrauten Anbieters in den öffentlich-rechtlichen Auftrag aufnehmen will oder nicht". 109

Diese Kriterien der Förmlichkeit und Transparenz könnten dahin verstanden werden, dass die in der Ministerpräsidentenkonferenz im März 2019 beschlossene Flexibilisierung der Beauftragung öffentlich-rechtlicher Angebote unionsrechtlich bedenklich ist. Dem stehen aber bereits zwei parallele Zielrichtungen der Reform entgegen:

- Die vorgesehene „Profilschärfung des Auftrags“, nach der ,in allen Bereichen künftig das öffentlich-rechtliche Profil der Angebote, das nicht marktwirtschaftlichen Anreizen folgt, sondern zu einer inhaltlichen Vielfalt beiträgt, die allein über den freien Markt nicht gewährleistet werden kann, als Gegengewicht zu den Angeboten der privaten Rundfunkanbieter stärker zum Ausdruck kommen (soll)“, wäre mit einer Definition des Auftrags verbunden, die die öffentlich-rechtliche besondere Qualität der Angebote stärkt und damit unter wettbewerbsrechtlicher Betrachtung die spezifische DaseinsvorsorgeQualität des öffentlich-rechtlichen Rundfunks zusätzlich fördern würde.

- Die Beauftragung öffentlich-rechtlicher Angebote soll zudem nach dem MPK-Beschluss „unter Beachtung der Erfordernisse des EU-Beihilfekompromisses“ flexibilisiert werden. Damit ist eine maßgebliche Berücksichtigung auch der Rundfunk-Mitteilung aus 2009 in der Fortentwicklung der Definition des öffentlich-rechtlichen Auftrags politisch vorgegeben.

Angesichts der Besonderheiten des Rundfunksektors und der Notwendigkeit zum Schutz der redaktionellen Unabhängigkeit der öffentlich-rechtlichen Rundfunkanstalten erscheint es zudem nach der Judikatur des Gerichts Erster Instanz unter Berücksichtigung der Ausle- 
gungsbestimmungen des Amsterdamer Protokolls im Allgemeinen legitim, eine qualitative Auftragsbestimmung als von Art. 106 Abs. 2 AEUV gedeckt anzusehen, der zufolge die betreffende Rundfunkanstalt mit der Aufgabe betraut wird, ein großes Programmspektrum (auch in Gestalt eines „Vollprogramms") ${ }^{110}$ und ein ausgewogenes und abwechslungsreiches Programm zu bieten. ${ }^{11}$

Die Auftragsdefinition muss nicht in Abgrenzung zum Angebot des privaten Rundfunks erfolgen und die Beihilfeaufsicht ist daher nicht darauf angelegt, einen Vergleich der Programme des öffentlich-rechtlichen Rundfunks mit denen der privaten Rundfunkveranstalter vorzunehmen. Denn ,die Definition der Dienstleistung von allgemeinem wirtschaftlichem Interesse im Bereich des Rundfunks mittels einer vergleichenden Programmanalyse vom Programmumfang der kommerziellen Fernsehanstalten abhängen zu lassen, würde dazu führen, dass den Mitgliedstaaten ihre Befugnis genommen würde, die gemeinwirtschaftliche Dienstleistung zu definieren. Die Definition der Dienstleistung von allgemeinem wirtschaftlichem Interesse hinge nämlich letztlich von den kommerziellen Anstalten und ihren Entscheidungen, bestimmte Programme auszustrahlen oder nicht, ab“. ${ }^{112}$

Eine solche, auch im Lichte der Judikatur breite Definition wird, worauf die Kommission in ihrer Rundfunkmitteilung 2009 hingewiesen hat, „im Allgemeinen als mit dem Ziel, die demokratischen, sozialen und kulturellen Bedürfnisse einer bestimmten Gesellschaft zu befriedigen und den Pluralismus, einschließlich der kulturellen und sprachlichen Vielfalt, zu wahren, im Einklang stehend erachtet“. Wie das Gericht erster Instanz festgestellt habe, „beruht die Rechtfertigung eines derart weit gefassten öffentlich-rechtlichen Auftrags auf den qualitativen Anforderungen, die an die Dienstleistungen öffentlich-rechtlicher Rundfunkanstalten gestellt werden". 113

Folgt man diesem Ansatz auch noch zehn Jahre später, wofür namentlich die fortdauernde Orientierung der Europäische Kommission an dieser Rundfunkmitteilung spricht, sind im Ausgangspunkt keine überzeugenden Gründe gegen eine flexiblere und damit offenere und ggf. weitere Definition des Auftrags von ARD und ZDF erkennbar, wenn diese -

110 EuG, Rs. T-442/03 [2008] SIC/Kommission [201].

111 A.a.O., Tz. 47 unter Bezugnahme auf EuG, Rs. T-442/03 [2008] SIC/Kommission [201] TV, Slg. 2008, II-1161 Rn. 201; verb. Rs.en T-309/04, T-317/04, T-329/04 und T-336/04, „TV 2“, Slg. 2008 II-2935 Rn. $122 \mathrm{ff}$.

112 EuG, verb. Rs.en T-309/04, T-317/04, T-329/04 und T-336/04 [2008] TV 2/Danmark [121-122].

113 Diese qualitativen Kriterien sind nach Auffassung des Gerichts erster Instanz „nämlich in der nationalen audiovisuellen Landschaft die Rechtfertigung für Dienstleistungen von allgemeinem wirtschaftlichem Interesse im Bereich des Rundfunks“. Es gibt aus Sicht des Gerichts „keinen Grund dafür, dass eine weit definierte Dienstleistung von allgemeinem wirtschaftlichem Interesse im Bereich des Rundfunks, für die von der Einhaltung dieser qualitativen Anforderungen abgesehen wird zugunsten eines Verhaltens eines kommerziellen Betreibers, das in einer speziell darauf ausgerichteten Programmgestaltung besteht, ein aus der Sicht der Werbeträger optimales Publikum zu gewinnen, vom Staat weiterhin zu denselben Bedingungen finanziert wird, wie wenn die qualitativen Voraussetzungen eingehalten würden“ (EuG, Rs. T-442/03 [2008] SIC/Kommission [211]). 
wie vorgesehen - mit einer Schärfung der qualitativen Anforderungen im Rahmen der vorgesehenen Profilschärfung verbunden wäre, die das öffentlich-rechtliche Profil der Angebote stärkt, indem sie zu einer inhaltlichen Vielfalt beiträgt, die allein über den freien Markt nicht gewährleistet werden kann. Dies kann z.B. auch über eine Stärkung des öffentlichrechtlichen Profils im Bereich der Unterhaltung erfolgen.

Bei der Auftragsdefinition verdient im Hinblick auf die fortdauernde Kontrollkompetenz der Europäischen Kommission in Bezug auf „offensichtliche Fehler“ dieser Definition Beachtung, dass die Rundfunkmitteilung 2009 von einem solchen Fehler ausging, wenn die Definition „Tätigkeiten umfasst, bei denen realistischerweise nicht davon auszugehen ist, dass sie - mit den Worten des Protokolls von Amsterdam - der Befriedigung der ,demokratischen, sozialen und kulturellen Bedürfnisse jeder Gesellschaft" dienen“. ${ }^{114}$ Dem könnte bei der geplanten Flexibilisierung des Auftrags fortdauernd durch einen negativen Katalog solcher Tätigkeiten, die ARD und ZDF nicht gestattet sind, Rechnung getragen werden ein Katalog, wie er sich aktuell bereits sowohl in Bezug auf das Jugendangebot von ARD und ZDF in der Anlage zu $\S 11 \mathrm{~g}$ Abs. 5 Satz 1 des Rundfunkstaatsvertrages als auch (seit Inkrafttreten des 22. Rundfunkänderungsstaatsvertrages am 1. Mai 2019 in geänderter Fassung) mit Blick auf Telemedienangebote in $\S 11 \mathrm{~d}$ Abs. 5 und 7 RStV sowie der Anlage zu $\S 11 \mathrm{~d}$ Abs. 5 Satz 4 RStV findet.

Zudem empfiehlt es sich nicht nur aus verfassungs-, sondern auch aus unionsrechtlicher Sicht, bei der Auftragsdefinition - sei es im Normtext, sei es in der Begründung des Textes, auf die besonderen Eigenschaften des öffentlich-rechtlichen Rundfunks einzugehen, die aus Sicht des BVerfG in seinem Rundfunkbeitragsurteil den Rundfunkbeitrag nicht nur als „Demokratieabgabe“ qualifizieren lassen, sondern auch dessen individuelle Vorteilhaftigkeit begründen: Indem der öffentlich-rechtliche Rundfunk jedenfalls im Wesentlichen öffentlich finanziert sei, werde er dazu befähigt, wirtschaftlich unter anderen Entscheidungsbedingungen zu handeln. Auf dieser Basis könne und solle er durch eigene Impulse und Perspektiven zur Angebotsvielfalt beitragen und unabhängig von Einschaltquoten und Werbeaufträgen ein Programm anbieten, das den verfassungsrechtlichen Anforderungen gegenständlicher und meinungsmäßiger Vielfalt entspricht. Zugleich könnten so im Nebeneinander von privatem und öffentlich-rechtlichem Rundfunk verschiedene Entscheidungsrationalitäten aufeinander einwirken. Diese Wirkungsmöglichkeiten gewännen zusätzliches Gewicht dadurch, dass die neuen Technologien eine Vergrößerung und Ausdifferenzierung des Angebots und der Verbreitungsformen und -wege gebracht sowie neuartige programmbezogene Dienstleistungen ermöglicht hätten. Allein der Umstand eines verbreiterten Angebots privaten Rundfunks und einer Anbietervielfalt führe für sich noch nicht zu Qualität und Vielfalt im Rundfunk. Die Digitalisierung der Medien und insbesondere die Netz- und Plattformökonomie des Internet einschließlich der sozialen Netzwerke begünstigten - im Gegenteil - Konzentrations- und Monopolisierungstendenzen bei Anbietern, Verbreitern und Vermittlern von Inhalten. Seien Angebote zum größten Teil werbefinanziert, förderten sie 
den publizistischen Wettbewerb nicht unbedingt; auch im Internet könnten die für die Werbewirtschaft interessanten größeren Reichweiten nur mit den massenattraktiven Programmen erreicht werden. Hinzu komme die Gefahr, dass - auch mit Hilfe von Algorithmen Inhalte gezielt auf Interessen und Neigungen der Nutzerinnen und Nutzer zugeschnitten werden, was wiederum zur Verstärkung gleichgerichteter Meinungen führe. Solche Angebote seien nicht auf Meinungsvielfalt gerichtet, sondern würden durch einseitige Interessen oder die wirtschaftliche Rationalität eines Geschäftsmodells bestimmt, nämlich die Verweildauer der Nutzer auf den Seiten möglichst zu maximieren und dadurch den Werbewert der Plattform für die Kunden zu erhöhen. Zudem träten verstärkt nicht-publizistische Anbieter ohne journalistische Zwischenaufbereitung auf. Dies alles führe zu schwieriger werdender Trennbarkeit zwischen Fakten und Meinung, Inhalt und Werbung sowie zu neuen Unsicherheiten hinsichtlich Glaubwürdigkeit von Quellen und Wertungen. ${ }^{115}$ „Angesichts dieser Entwicklung wächst die Bedeutung der dem beitragsfinanzierten öffentlich-rechtlichen Rundfunk obliegenden Aufgabe, durch authentische, sorgfältig recherchierte Informationen, die Fakten und Meinungen auseinanderhalten, die Wirklichkeit nicht verzerrt darzustellen und das Sensationelle nicht in den Vordergrund zu rücken, vielmehr ein vielfaltssicherndes und Orientierungshilfe bietendes Gegengewicht zu bilden“. ${ }^{116}$

\section{b) Betrauung und Kontrolle}

Damit die Ausnahmeregelung des Art. 106 Abs. 2 AEUV Anwendung finden kann, sollten die öffentlich-rechtlichen Rundfunkanstalten nach der Rundfunkmitteilung ,z. B. durch einen Rechtsakt, einen Vertrag oder eine bindende Aufgabenbeschreibung“ „förmlich“ mit dem öffentlich-rechtlichen Auftrag betraut werden. ${ }^{117}$

Damit stehen verschiedene Möglichkeiten zur Verfügung, der Förmlichkeit des Betrauungsaktes zu genügen. Eine Versteinerung dahingehend, dass nur bislang genutzte Instrumente für eine Anpassung des Auftrages zur Verfügung stehen, existiert nicht.

Der Betrauungsakt muss allerdings ,eine genaue Definition der gemeinwirtschaftlichen Verpflichtungen, die Voraussetzungen für die Gewährung des Ausgleichs sowie Bestimmungen zur Vermeidung von Überkompensierung und zur Rückzahlung entsprechender Beträge enthalten“. 118

Nicht zuletzt mit Blick auf das Modellen einer umfassenden Indexierung der Anpassung der Höhe des Rundfunkbeitrags inhärente Risiko einer Überkompensierung verdienen diese Vorgaben der Rundfunkmitteilung für den Betrauungsakt bei den weiteren medienpo-

115 Vgl. BVerfG, Urteil des Ersten Senats vom 18. Juli 2018 - 1 BvR 1675/16 - [75-80].

116 BVerfG, Urteil des Ersten Senats vom 18. Juli 2018 - 1 BvR 1675/16 - [80] unter Bezugnahme auf Brinkmann, ZUM 2013, 193 (195, 198); Dörr, Holznagel \& Picot, ZUM 2016, 920 (936 f., 940 f.); Drexl, ZUM 2017, 529 (530 ff.); Langbauer \& Ripel, MMR 2015, 572 (573); Milker, ZUM 2017, 216 (221).

117 Europäische Kommission (2009), Tz. 50.

118 A.a.O., Tz. 51. 
litischen Erörterungen besondere Beachtung. Das Risiko der Überkompensierung steht allerdings auch im Lichte der Rundfunkmitteilung einer Einführung einer „Vollindexierung“ nicht bereits im Ansatz entgegen, solange die aufgezeigten Absicherungen zur Vermeidung von Überkompensierung sowie zur Rückzahlung entsprechender Beträge in einen entsprechenden Systemwechsel eingebunden werden. Diesen Vorgaben kann nicht zuletzt durch eine fortdauernde Berücksichtigung der KEF als Anwalt von Wirtschaftlichkeit und Sparsamkeit in einem Systemwechsel Rechnung getragen werden. ${ }^{119}$

In der Rundfunkmitteilung wird im Übrigen nicht nur ein förmlicher Betrauungsakt, sondern auch gefordert, dass die öffentlich-rechtliche Dienstleistung tatsächlich so erbracht wird, wie dies im Betrauungsakt vorgesehen ist. Daher sei es „wünschenswert“, dass eine geeignete Behörde oder benannte Stelle die Einhaltung der Vereinbarung transparent und wirksam kontrolliert. ${ }^{120}$ Im Hinblick auf die Qualitätsstandards kann dies nach der bisherigen Aufgabenstellung der KEF diese zumindest dort nicht sein, wo es um solche Standards inhaltlicher Art - nicht zuletzt i.S. der geplanten programmlichen Profilschärfung - geht.

$\mathrm{Ob}$ die binnenpluralen Kontrollgremien bei den ARD-Anstalten und beim ZDF diese Kontrollaufgabe effektiv wahrnehmen können und wahrnehmen, wird zwar in der Literatur kontrovers diskutiert. ${ }^{121}$ In der Rechtsprechung des BVerfG, namentlich dessen ZDF-Urteil aus 2014, ist diese Kontrollbefähigung und -willigkeit indessen zumindest inzident anerkannt. ${ }^{122}$ Von dessen spezifisch öffentlichem Funktionsauftrag ausgehend ,ist seine Organisation als öffentlich-rechtliche Anstalt mit einer binnenpluralistischen Struktur, bei welcher der Einfluss der in Betracht kommenden Kräfte unter maßgeblicher Einbeziehung der Zivilgesellschaft intern im Rahmen von Kollegialorganen vermittelt wird, weiterhin verfassungsrechtlich nicht zu beanstanden... Sie überlässt nicht allein einem Intendanten die Leitung der Geschäfte, sondern bindet diesen in eine umfassende Aufsicht durch plural zusammengesetzte Gremien ein und unterwirft ihn damit einer Kontrolle." Wird ein solches binnenpluralistisches Modell gewählt, um die Vielfaltsicherung durch den öffentlich-rechtlichen Rundfunk zu gewährleisten, ist freilich auch die nähere Ausgestaltung der Organisation an diesem Funktionsauftrag zu orientieren. „Hierfür bedarf es insbesondere einer sachgerechten, der gesellschaftlichen Vielfalt Rechnung tragenden Bestimmung und Gewichtung der in den Gremien berücksichtigten Kräfte sowie der Sicherstellung eines effektiven Einflusses auf die Wahrnehmung des Rundfunkauftrags durch diejenigen Organe, in denen diese vertreten sind.“ „Die Bildung der Aufsichtsgremien aus vorwiegend verbandlich orga-

119 Eine Frage, die bei einem Wechsel zu einem System der „Vollindexierung“ zu klären ist, ist, welche Auswirkungen es hat, wenn die KEF eine Überkompensierung moniert. Sofern in einem solchen Fall eine Korrektur-Kompetenz einer dritten Seite, namentlich der Landesparlamente, bestehen sollte, wäre eine „Entpolitisierung“ des Verfahrens erkennbar nicht mehr gegeben.

120 Europäische Kommission (2009), Tz. 53.

121 Vgl. einerseits z.B. Ritlewski (2009), S. 274 ff., andererseits z.B. Elixmann (2016), S. 140; zur Diskussionslage fortdauernd relevant Lilienthal (2009).

$122 \mathrm{Zu}$ den folgenden Zitaten BVerfGE 136, 9 (30 ff.) unter Bezugnahme auf BVerfGE 12, 205 (261 ff.); 83, 238 (333). 
nisierten gesellschaftlichen Gruppen hat nicht den Sinn, diesen die Programmgestaltung zu übertragen oder sie gar zum Träger des Grundrechts der Rundfunkfreiheit zu machen. Die Aufsichtsgremien sind vielmehr Sachwalter des Interesses der Allgemeinheit. Sie sollen die für die Programmgestaltung maßgeblichen Personen und Gremien darauf kontrollieren, dass alle bedeutsamen politischen, weltanschaulichen und gesellschaftlichen Kräfte, deren Vielfalt durch ein gruppenplural zusammengesetztes Gremium auch bei ausgewogener Besetzung nie vollständig oder repräsentativ abgebildet werden kann, im Gesamtprogramm angemessen zu Wort kommen können.“

Auch mit Blick auf das sich entwickelnde Kooperationsverhältnis zwischen EuGH und BVerfG ${ }^{123}$ spricht wenig dafür, dass die Gerichte der EU insoweit durchgreifende Bedenken anmelden werden. Dagegen spricht insbesondere auch, dass sich das BVerfG selbst in seiner ZDF-Entscheidung u.a. auf die Rechtsprechung des Europäische Gerichtshofs für Menschenrechte stützt, dessen Judikatur ihrerseits diejenige des EuGH im grundrechtssensiblen Bereich mitbestimmt. ${ }^{124}$ Aus Sicht des BVerfG ${ }^{125}$ „entsprechen (die aufgezeigten Erfordernisse) den Anforderungen der Europäischen Menschenrechtskonvention. Nach der Auslegung des Europäischen Gerichtshofs für Menschenrechte verpflichtet Art. 10 EMRK die Konventionsstaaten, durch gesetzliche Ausgestaltung die Vielfalt im Rundfunk zu gewährleisten und diese Pflicht insbesondere nicht dadurch zu unterwandern, dass eine gewichtige ökonomische oder politische Gruppe oder der Staat eine dominante Position über eine Rundfunkanstalt oder innerhalb einer Rundfunkanstalt einnehmen kann und hierdurch Druck auf die Veranstalter ausüben kann“. 126

\section{c) Wahl des Systems zur Finanzierung des öffentlich-rechtlichen Rundfunks}

In der Rundfunkmitteilung betont die Kommission unter Bezugnahme auf das Amsterdamer Protokoll, dass sie „keine grundsätzlichen Einwände gegen die Wahl einer Mischfinanzierung anstelle einer Einzelfinanzierung “ habe. ${ }^{127}$

Eine Kombination von Mitteln aus dem Rundfunkbeitragsaufkommen und Einnahmen aus kommerziellen Tätigkeiten und Tätigkeiten aufgrund des öffentlich-rechtlichen Auf-

123 Vgl. BVerfGE 89, 155 (175) (st. Rspr.).

Die Erschaffung eines wirklichen Kooperationsverhältnisses zwischen dem EuGH und den nationale Verfassungsgerichten hat zwar ihren Ausgangspunkt nicht zuletzt auch in diesen Überlegungen des BVerfG. Allerdings hat der EuGH jüngst im Ringen um das "Letztentscheidungsrecht" eine gewisse Offenheit erkennen lassen, mitgliedstaatliche Strukturprinzipien wie den Grundsatz der Gesetzmäßigkeit bei der Anwendung und Auslegung des Unionsrechts zu beachten; vgl. EuGH, Rs. C-42/17 [2018] M.A.S. u. M.B. [41-62].

124 Vgl. hierzu z.B. Engel (2015), S. 71 ff.; Haratsch, ZaöRV 2006, 927 (933 f.).

125 BVerfGE 136, 9 (36 f.).

126 Das BVerfG stützt sich insoweit auf EGMR, Manole and Others v. Moldova, no. 13936/02, $\S \S 95-102$; EGMR (GK), Centro Europa 7 S.r.l. u.a. v. Italien, Urteil vom 7. Juni 2012, Nr. 38433/09, NVwZ-RR 2014, S. 48 (52 f.), §§ 129 ff.

127 Vgl. Europäische Kommission (2009), Tz. 58. 
trags wie z.B. dem Verkauf von Sendezeit für Werbung ist mithin unionsrechtlich nicht bereits als solche Bedenken ausgesetzt. Der Finanzierungstyp für ARD und ZDF als solcher bliebe vom Wechsel hin zu einem System der „Vollindexierung“ im Übrigen unberührt. Ein sukzessiver Verzicht auf werbliche Ko-Finanzierung bzw. Ko-Finanzierung aus Mitteln kommerzieller Kommunikation, wozu außer dem - ARD und ZDF ohnedies nach Maßgabe des $\S 18 \mathrm{RStV}$ untersagten - Teleshopping neben Werbung (in den zeitlichen Grenzen des $\S 16$ Abs. 1 bis 3 RStV für Fernsehen und des $\S 16$ Abs. 5 RStV für Hörfunk) auch Sponsoring (in den zeitlichen Grenzen des $§ 16$ Abs. 6 RStV) zählt, könnte in einer Gesamtschau die beihilfeaufsichtsrechtliche Prüfung zu Gunsten der deutschen Länder beeinflussen - unabweisbar ist dieser Konnex allerdings nicht.

\section{d) Transparenzanforderungen bei der Prüfung der staatlichen Beihilfe}

Die spezifischen Transparenzanforderungen nach der Rundfunkmitteilung in Bezug auf eine klare und angemessene Trennung zwischen öffentlich-rechtlichen Tätigkeiten und sonstigen Tätigkeiten einschließlich klar getrennter Buchführung ${ }^{128}$ werden durch einen Übergang zu einer umfassend indexgestützten Entwicklung der Höhe des Rundfunkbeitrags nicht zwingend beeinträchtigt. Die in den $\S \S 16 a$ ff. RStV und den ergänzenden landesmedienrechtlichen Regelungen insoweit enthaltenen Absicherungen bedürfen bei diesem Übergang nicht systemimmanent einer Korrektur.

\section{e) Nettokostenprinzip und Überkompensierung}

Da eine Überkompensierung für die Erbringung einer Dienstleistung von allgemeinem wirtschaftlichem Interesse nicht erforderlich ist, stellt eine Überkompensierung nach der Rundfunkmitteilung grundsätzlich eine mit dem Gemeinsamen Markt unvereinbare Beihilfe dar, die zurückzuzahlen ist. ${ }^{129}$

Um der Verhältnismäßigkeitsprüfung zu genügen, darf der Betrag der öffentlichen Ausgleichszahlung ,grundsätzlich die Nettokosten des öffentlich-rechtlichen Auftrags auch unter Berücksichtigung anderer direkter oder indirekter Einnahmen aus diesem Auftrag nicht übersteigen". 130

Zulässig ist damit unionsrechtlich durchaus eine Unterschreitung: Während eine solche Unterschreitung des zur Auftragserfüllung gebotenen Beihilfeniveaus verfassungsrechtlich durchgreifenden Bedenken im Hinblick auf das Gebot einer funktions- und bedarfsgerechten Finanzausstattung begegnen würde, ${ }^{131}$ gibt es unionsrechtlich weder einen Anspruch

128 A.a.O., Tz. $60 \mathrm{ff}$.

129 A.a.O., Tz. 70.

130 Daher werden nach der Rundfunkmitteilung (a.a.O., Tz. 71) bei der Berechnung der Nettokosten der öffentlich-rechtlichen Dienstleistungen die Nettogewinne aus allen kommerziellen Tätigkeiten berücksichtigt, die mit den öffentlich-rechtlichen Tätigkeiten in Verbindung stehen.

131 Vgl. Hoffmann-Riem (1991), S. 23. 
auf Beihilfe noch auf Daseinsvorsorge-Absicherung: Mit dem Übergang zu einer Vollindexierung verbundene Zielsetzungen der Kostendämpfung, Begrenzung, realen Reduzierung oder gar (im Falle eines zumindest theoretisch denkbaren negativen Index) juristischen Absenkung der Höhe des Rundfunkbeitrages ${ }^{132}$ sind aus unionsrechtlicher Perspektive nicht per se rechtswidrig. „Programmneutralität“ und „Programmakzessorietät“ 133 sind verfassungsrechtliche Vorgaben für die Rechtskonformität der Finanzausstattung des öffentlichrechtlichen Rundfunks i.S. eines verfassungsrechtlichen Unterschreitungsgebotes, nicht zugleich auch unmittelbar oder inzident unionsrechtliche Vorgaben für die Rechtskonformität der Rundfunkfinanzverfassung unter beihilfeaufsichtlicher Prüfperspektive i.S. eines parallelen unionsrechtlichen Unterschreitungsgebotes.

Allerdings muss sich jede Reform der Rundfunkfinanzierung am doppelten Prüfungsmaßstab des Unions- wie des Verfassungsrechts messen lassen. Eine unionsrechtliche Unbedenklichkeit ist verfassungsrechtlich insoweit ohne Präjudizwirkung. Dies gilt in gleicher Weise auch umgekehrt: Während der Finanzbedarf des öffentlich-rechtlichen Rundfunks durch eine gesetzliche rsp. staatsvertragliche Ausdehnung des Auftrags der öffentlich-rechtlichen Anstalten über das Funktionserforderliche hinaus ggf. verfassungsfest ausgedehnt werden kann, ${ }^{134}$ begegnen solche Ausdehnungen unionsrechtlich erheblichen Bedenken mit Blick auf das Wettbewerbsregime des AEUV: Auch wenn die unionsrechtlich gebotene Auftragsdefinition nicht dergestalt vorstrukturiert ist, dass sie den Rahmen des verfassungsrechtlich i.S. der Funktionserforderlichkeit gesetzten Rahmen nicht überschreiten darf, so gewinnt die Kompetenz zur beihilfeaufsichtsrechtlichen Missbrauchskontrolle umso stärker an Gewicht, je diffuser und entgrenzter die Auftragsdefinition erfolgt.

Generelle Präjudizwirkungen jeweiliger Kontrollentscheidungen sind der Zuordnung von unionaler Wettbewerbs- und verfassungsgestützter Rundfunkfinanzordnung mithin wechselseitig fremd. Aus einer offenen und grenzenlosen innerstaatlichen Gestaltung der Definition des Auftrags des öffentlich-rechtlichen Rundfunks erwächst kein Anspruch auf beihilfeaufsichtsrechtliche Freizeichnung einer finanziellen Unterstützung (und damit einhergehend eine Entgrenzung des Beitragsaufkommens zur Finanzierung der Erfüllung eines entsprechenden Auftrags). Von daher gibt es bei in erheblichem Umfang finanzwirksamen Änderungen des Auftrags ein Risiko, dass die Europäische Kommission (und ihr folgend auch die Gerichte der EU) das Kriterium der Überkompensierung vom Anknüpfungspunkt der Auftragsdefinition löst. Mögliche Spannungen zwischen gesetzlicher Auftragsdefinition, Programmgestaltungsfreiheit der öffentlich-rechtlichen Anstalten und der Verpflichtung zu Wirtschaftlichkeit und Sparsamkeit bedürfen deshalb in einem etwaigen Übergang zu einer „Vollindexierung“ nicht nur aus verfassungs-, ${ }^{135}$ sondern auch aus unionsrechtlichen

$132 \mathrm{Zu}$ solchen Zielen vgl. Cornils (2019), S. 5 unter Hinweis auf die Debatte im Vereinigten Königreich; zu letzterer Nickel, ZUM 2006, 737 (739).

133 BVerfGE 90, 60 (94).

134 Vgl. Cornils (2019), S. 18.

135 Vgl. a.a.O., S. $24 \mathrm{f}$. 
Gründen der Verankerung einer periodischen Evaluierung fortdauernder Rechtskonformität des Systems der Rundfunkfinanzierung und einer Korrekturoption im Falle evidenter Verletzung des Gebotes der Angemessenheit von Auftragsdefinition und -erfüllung.

Zwar dürfen Unternehmen, die für die Erfüllung eines öffentlich-rechtlichen Auftrags einen Ausgleich erhalten, „in der Regel einen angemessenen Gewinn erzielen“. ${ }^{136}$ Im Rundfunksektor wird der öffentlich-rechtliche Auftrag allerdings aus Sicht der Kommission meist von Rundfunkanstalten erfüllt, die nicht gewinnorientiert sind bzw. keine Kapitalrendite erzielen müssen und die keine Tätigkeiten außerhalb des öffentlich-rechtlichen Auftrags ausführen. Nach Auffassung der Kommission ist es in einer solchen Situation nicht angemessen, in den Ausgleich für die Erfüllung des öffentlich-rechtlichen Auftrags ein Gewinnelement einzubeziehen. Die öffentlich-rechtlichen Rundfunkanstalten dürfen jedoch selbstverständlich mit kommerziellen Tätigkeiten außerhalb des öffentlich-rechtlichen Auftrags Gewinne erzielen. ${ }^{137}$

Öffentlich-rechtliche Rundfunkanstalten dürfen aus Sicht der Kommission ${ }^{138}$ zudem über die Nettokosten der öffentlich-rechtlichen Dienstleistungen hinausgehende jährliche Überkompensierungen (in Form von „Rücklagen für öffentlich-rechtliche Dienstleistungen“) in dem Maße einbehalten, wie dies für die Sicherung der Finanzierung ihrer gemeinwirtschaftlichen Verpflichtungen erforderlich ist. Die Kommission ist im Allgemeinen der Auffassung, dass es als erforderlich angesehen werden kann, einen Betrag von bis zu $10 \%$ der im Rahmen des öffentlich-rechtlichen Auftrags veranschlagten jährlichen Ausgaben einzubehalten, um Kosten- und Einnahmenschwankungen auffangen zu können. Darüber hinausgehende Überkompensierungen sind in der Regel ohne unangemessene Verzögerung zurückzufordern.

„Nur in hinreichend begründeten Ausnahmefällen darf öffentlich-rechtlichen Rundfunkanstalten gestattet werden, Beträge einzubehalten, die $10 \%$ der im Rahmen ihres öffentlich-rechtlichen Auftrags veranschlagten jährlichen Ausgaben übersteigen. Dies ist nur dann zulässig, wenn diese Überkompensierung vorab verbindlich für einen bestimmten Zweck vorgemerkt wird, bei dem es sich um eine nicht wiederkehrende, erhebliche Ausgabe handeln muss, die für die Erfüllung des öffentlich-rechtlichen Auftrags erforderlich ist". 139

Im Hinblick auf den engen Ausnahmecharakter dieser Öffnungsklausel, auf die erkennbar nicht generell, sondern nur in einem konkreten Einzelfall Bezug genommen werden kann, würde eine verallgemeinernde Nutzung dieser Öffnung mit erheblichen unionsrechtlichen Risiken behaftet sein. Es empfiehlt sich daher - ungeachtet der seitens der Kommission im (zeitlich vorgelagerten) Beihilfekompromiss aufgezeigten Bereitschaft zu einer grö-

136 Dieser Gewinn besteht in einem Eigenkapitalrenditesatz, der sich aus den von dem Unternehmen getragenen bzw. nicht getragenen Risiken ergibt; vgl. Europäische Kommission (2009), Tz. 72 ff.

137 A.a.O., Fn. 47.

138 A.a.O., Tz. 73

139 A.a.O., Tz. 74 
ßere Flexibilität ${ }^{140}$ - im Falle eines Übergangs zu einer „Vollindexierung“ die genannte $10 \%$-Schranke einer etwaigen Überkompensierung, wie sie dem neuen Modell als Risiko inhärent wäre, strikt zu beachten. ${ }^{141}$

\section{f) Finanzaufsichtsmechanismen}

Die Mitgliedstaaten haben nach der Rundfunkmitteilung zudem geeignete Mechanismen einzurichten, um sicherzustellen, dass es grundsätzlich nicht zu einer Überkompensierung kommt. Sie haben hierzu eine regelmäßige und wirksame Aufsicht über die Verwendung der öffentlichen Finanzmittel zu gewährleisten, um Überkompensierung und Quersubventionierung auszuschließen sowie Höhe und Verwendung der „Rücklagen für öffentlichrechtliche Dienstleistungen“" zu kontrollieren. ${ }^{142}$

Damit erfährt die KEF in ihrer jetzigen Zusammen- und Aufgabensetzung zwar keine unionsrechtliche Absicherung - Änderungen im KEF-Verfahren sind im Übergang zu einem Vollindexierungsmodell durch die Rundfunkmitteilung mithin weder verfassungs- ${ }^{143}$ noch unionsrechtlich gänzlich ausgeschlossen. Eine unionsrechtliche Versteinerung von konkreten mitgliedstaatlichen Aufsichts- und Kontrollstrukturen wäre mit der grundsätzlichen unionsrechtlichen Beachtung der mitgliedstaatlichen Souveränität im Bereich der Verwaltungsorganisation ${ }^{144}$ kaum in Deckung zu bringen. Allerdings ist zugleich evident, dass das bisherige KEF-Verfahren in besonderer Weise den Anforderungen der Rundfunkmitteilung an den gebotenen Finanzaufsichtsmechanismus Rechnung trägt. Klar ist zudem, dass ein ersatzloser Verzicht auf das KEF-Verfahren mit den Vorgaben der Rundfunkmitteilung nicht vereinbar wäre und eine staatsvertragliche Reform insoweit mit dem hohen Risiko des Scheiterns vor unionalen Kontrollgremien belasten würde.

\section{Der Beihilfekompromiss aus 2007}

\section{Einleitung}

Die Kommission hat die frühere Gebührenfinanzierung von ARD und ZDF mit Entscheidung vom 24. April 2007 als bestehende Beihilfe anerkannt. ${ }^{145}$ Dieser sog. Beihilfekom-

140 Vgl. hierzu Abschnitt VII.4.c).

141 Zudem sind nach der Rundfunkmitteilung die Bedingungen, zu denen die öffentlich-rechtlichen Rundfunkanstalten die Überkompensierungen verwenden dürfen, festzulegen, wobei eine Verwendung nur für die Finanzierung öffentlich-rechtlicher Tätigkeiten in Betracht kommt. Eine Quersubventionierung kommerzieller Tätigkeiten ist nicht gerechtfertigt und stellt eine mit dem Gemeinsamen Markt unvereinbare staatliche Beihilfe dar. Vgl. Europäische Kommission (2009), Tz. $75 \mathrm{f}$.

142 Vgl. a.a.O., Tz. 77.

143 Vgl. Cornils (2019), S. 26 f.

144 Vgl. z.B. Frenz (2010), Rn. 1740 ff.

145 Europäische Kommission (2007), Tz. 216. 
promiss bildete den Abschluss eines von der Kommission am 3. März 2005 eingeleiteten Verfahrens zur Überprüfung der Gebührenfinanzierung der öffentlich-rechtlichen Rundfunkanstalten als bestehender Beihilfen.

Der Beihilfekompromiss dürfte Referenzdokument für eine Überprüfung eines Übergangs zu einer umfassend indexgestützten Entwicklung der Höhe des Rundfunkbeitrags in Deutschland durch die Kommission bleiben. Hieran dürfte auch der zwischenzeitlich bereits erfolgte Umstieg von einer Gebühren- zu einer Beitragsfinanzierung nichts ändern. Vor diesem Hintergrund sollen im Folgenden wesentliche Elemente der Entscheidung der Kommission auf ihre voraussichtliche Bewertung einer „Vollindexierung“ untersucht werden.

\section{Beihilfecharakter}

Die Kommission hat in ihrer Entscheidung 2007 die Auffassung vertreten, „dass es sich bei der Finanzierungsgarantie (einschließlich der uneingeschränkten staatlichen Garantie aufgrund der Tatsache, dass es sich bei den öffentlich-rechtlichen Rundfunksendern um Anstalten handelt) und der Gebührenfinanzierung um eine staatliche Beihilfe im Sinne des Artikels 87 Absatz 1 EG-Vertrag handelt““. 146

Es spricht nichts dafür, dass der Übergang zu einer „Vollindexierung“ eine Umkehr zu einer Verneinung des Beihilfecharakters des entsprechend modifizierten Systems der Beitragsfinanzierung für ARD und ZDF seitens der Kommission auslösen wird.

\section{Bestehende Beihilfe}

Nach Auffassung der Kommission konnten ,sowohl die Finanzierungsgarantie als auch die Gebührenfinanzierung von ARD und ZDF in ihrer jetzigen Form und ihrem jetzigen Umfang als bestehende Beihilfe angesehen werden“. ${ }^{147}$ Die Kommission berücksichtigte bei dieser Einordnung zunächst, ${ }^{148}$ dass die Finanzierungsregelung für den öffentlich-rechtlichen Rundfunk vor Inkrafttreten des EWG-Vertrags eingeführt wurde. Sie erachtete sodann mehrere zwischenzeitliche Änderungen als unbeachtlich im Hinblick auf die Einordnung als „,bestehende“ Beihilfe, da diese Änderungen ,weder von der ursprünglichen Finanzierungsregelung abtrennbar (seien), noch... sie deren wesentlichen Charakter (berührten)“ ${ }^{149}$

Besondere Bedeutung im Hinblick auf eine Risikoprognose kommt der Einordnung des 1997 eingeführten „KEF-Verfahrens“ durch die Kommission zu. Dieses habe „eine Änderung der Methodik und des Verfahrens zur Ermittlung des Finanzbedarfs der öffentlichrechtlichen Rundfunkanstalten (betroffen). Die KEF als solche bestand bereits zuvor, hatte 
jedoch nur beratende Funktion. Durch die neuen Rahmenbedingungen wurde ihre Unabhängigkeit gestärkt. Da das Verfahren zur Ermittlung des Finanzbedarfs der öffentlich-rechtlichen Rundfunkanstalten integraler Bestandteil der Finanzierungsregelung ist, können die betreffenden Änderungen nicht von der ursprünglichen Finanzierungsregelung getrennt werden. Im Einklang mit der bisherigen Praxis der Kommission können diese Änderungen daher als Änderungen administrativer und technischer Art angesehen werden, die den wesentlichen Charakter der Finanzierungsregelung nicht berühren."150

Es erscheint im Lichte dieser Ausführungen zur sog. KEF-Klausel fraglich, ob auch ein Übergang zu einer umfassend indexgestützten Methode der Ermittlung der Höhe des Rundfunkbeitrags seitens der Kommission als bloße „Änderung administrativer und technischer Art“ angesehen werden wird, die „den wesentlichen Charakter“ der Finanzierungsregelung nicht berührt.

Denn erstens ist ein Ansatz einer solchen „Vollindexierung“ dem bisherigen deutschen Rundfunkfinanzierungssystem fremd. Zwar kennt dieses die Einbindung von einzelnen Indizes in die Prüfverfahren der KEF. Ob dies aus Sicht der Kommission allerdings ausreicht, um einen umfassenden Indexierungsansatz als bloße Weiterentwicklung dieser Ansätze zu verstehen, erscheint offen: Für eine solche Einordnung könnte sprechen, dass die KEF mit dem „Indexgestützten und integrierten Prüf- und Berechnungsverfahren (IIVF)“ ein Methodenheft für eine objektivierte und transparente Ermittlung des Finanzbedarfs der Rundfunkanstalten entwickelt hat. Schon die prominente Einbindung des Faktors „Index“ in den Namen dieses Systems verdeutlicht, dass bereits derzeit, d.h. bei einer bestehenden Beihilfe, „viel mit - allerdings differenzierten - Indizes gearbeitet wird. Etwa $80 \%$ des Aufwands sind indexiert. Nicht indexiert sind im Wesentlichen die Altersversorgung, die Programmverbreitung, die Investitionen, die Entwicklungsprojekte und die anrechenbaren Eigenmittel“. ${ }^{151}$ Gegen eine Einordnung als „bestehende Beihilfe“ ungeachtet des IIVF-Ansatzes der KEF könnte allerdings sprechen, dass eine „Vollindexierung“ beim derzeitigen Planungsstand offenbar zum einen von differenzierten Indizes in Richtung auf einen einheitlichen Index Abschied nehmen will und zum anderen auf das Gesamtsystem der Finanzierung - d.h. Aufwand und Ertrag - in vollem Umfang, d.h. zu $100 \%$, Anwendung finden soll.

Zudem ist zweitens nach dem derzeitigen Beratungsstand noch nicht sicher, ob die Rolle der KEF (oder eines vergleichbaren Kontrollgremiums) im Zuge des Übergangs zu einer umfassend indexgestützten Methode der zukünftigen Ermittlung der Höhe des Rundfunkbeitrags gestärkt wird. Eine Rückkehr zu einer lediglich beratenden Funktion der KEF wäre zwar eine Rückkehr zu einem status quo ante - allerdings zu einem status quo ante, der zu einer Zeit bestand, als das Unionsrecht selbst noch keine Regelungen zur funktionsgerechten Kontrolle der Wahrung der Vorgaben an Einrichtungen der Daseinsvorsorge kannte.

Besonderes Risikopotential weist im Lichte der Ausführungen zu „,bestehenden Beihilfen“ in der Entscheidung aus 2007 zudem eine etwaige Verknüpfung einer Flexibilisierung

150 A.a.O., Tz. 205.

151 Hirschle (2019), S. 5. 
des öffentlich-rechtlichen Auftrags mit einer Rücknahme in der Kontrolldichte bei der Finanzierung eines solchen weniger als bislang im Vorhinein gesetzlich fixierten Auftragsrahmens auf. Wenig spricht dafür, dass es sich bei einer solchen doppelten und kombinierten Flexibilisierung um bloße Änderungen administrativer und technischer Art handeln würde. Erhöhungen des Rundfunkbeitrags dürften zumindest bei einer solchen Kombination kaum noch als bloße „Konsequenz eines gestiegenen Finanzbedarfs der öffentlich-rechtlichen Rundfunkanstalten bei der Erfüllung ihres öffentlich-rechtlichen Auftrags “152 eingeordnet werden. Denn der Auftrag wäre zum einen deutlich weniger als bislang staatlich vorstrukturiert und Erhöhungen des Rundfunkbeitrags wären nicht Ergebnis eines nachweislich gestiegenen Finanzbedarfs von ARD und ZDF, sondern von Steigerungen der Kosten bei Faktoren, die beim Index aufgegriffen werden.

\section{Vereinbarkeit der Finanzierungsregelung mit dem Gemeinsamen Markt}

Die Vereinbarkeit der deutschen Finanzierungsregelung mit dem Gemeinsamen Markt hat die Kommission 2007 nach Art. 86 Abs. 2 EGV (nunmehr: Art. 106 Abs. 2 AUV), dem Amsterdamer Protokoll sowie der damaligen Rundfunkmitteilung bewertet. ${ }^{153}$ Dieses Normenmaterial dürfte die Europäische Kommission auch einer Bewertung eines umfassend indexgestützten Beihilfesystems zugrunde legen.

\section{a) Definition}

Die Kommission verweist insoweit ${ }^{154}$ auf die Vorgaben der damaligen Rundfunkmitteilung, die sich im hier interessierenden Bereich mit deren Neufassung 2009 nicht entscheidungsrelevant verändert haben. Die Definition des öffentlich-rechtlichen Auftrags fällt danach in die Zuständigkeit der nach der deutschen Verfassungsordnung hierfür zuständigen Länder; die Rolle der Kommission beschränkt sich auf eine Überprüfung auf offensichtliche Fehler, wobei ein solcher namentlich dann vorliegt, wenn dieser Auftrag auch Tätigkeiten umfasst, die nicht i.S. des Amsterdamer Protokolls den ,demokratischen, sozialen und kulturellen Bedürfnissen jeder Gesellschaft“ entsprechen. Eine „breit gefasste“ Definition ist zwar unionsrechtlich unbedenklich und kann auch neuartige Dienste umfassen, die keine „Programme“ im traditionellen Sinne sind, sofern diese - auch unter Berücksichtigung der Entwicklung und Diversifizierung der Tätigkeiten im digitalen Zeitalter - denselben demokratischen, sozialen und kulturellen Bedürfnissen der Gesellschaft dienen.

Allerdings ,muss die Definition der Mitgliedstaaten hinreichend präzise und klar sein“. Aus dieser Definition „,sollte unmissverständlich hervorgehen, ob der Mitgliedstaat eine bestimmte Tätigkeit der jeweiligen Anstalt in den öffentlich-rechtlichen Auftrag aufnehmen

152 Europäische Kommission (2007), Tz. 206.

153 A.a.O., Tz. 217.

154 A.a.O., Tz. $220 \mathrm{ff}$. 
will oder nicht". ${ }^{155} \mathrm{Ob}$ diese Präzision und Klarheit in der Definition des Auftrags bei einer geplanten Flexibilisierung noch erreichbar ist, kann beim derzeitigen Beratungsstand ungeachtet der geplanten Profilschärfung - dahin, dass ,,in allen Bereichen künftig das öffentlich-rechtliche Profil der Angebote, das nicht marktwirtschaftlichen Anreizen folgt, sondern zu einer inhaltlichen Vielfalt beiträgt, die allein über den freien Markt nicht gewährleistet werden kann, als Gegengewicht zu den Angeboten der privaten Rundfunkanbieter stärker zum Ausdruck kommen soll“" - noch nicht abschließend eingeschätzt werden. Ein RisikoMerkposten ist auf jeden Fall gegeben.

Dafür, dass dieses Risiko kein unbeachtliches ist, spricht die damalige Haltung der Kommission zur Auftragsdefinition hinsichtlich der digitalen Zusatzkanäle und hinsichtlich der neuen Mediendienste, bei denen die Kommission eine hinreichende Klarheit der Definition jeweils verneinte. Im Blick auf die geplante Flexibilisierung verdienen dabei als Risikofaktor namentlich folgende Passagen in der Entscheidung zu den neuen Mediendiensten Beachtung:

„Die Kommission vertritt... die Auffassung, dass eine allgemeine Ermächtigung der öffentlich-rechtlichen Rundfunkanstalten zur Erbringung nur unscharf definierter neuen Mediendienste und die daraus resultierende mangelnde Vorhersehbarkeit des Umfangs solcher Dienste für Dritte die Gefahr birgt, dass andere Marktteilnehmer davon abgehalten werden, solche neuen Mediendienste zu entwickeln und anzubieten. Eine klare Auftragsdefinition ist auch wichtig, um ein angemessenes Gleichgewicht zwischen der Erbringung von Diensten von allgemeinem wirtschaftlichem Interesse und der Schaffung gleicher Rahmenbedingungen für öffentliche und private Betreiber herzustellen und damit sicherzustellen, dass die Finanzierung neuer Mediendienste nicht dem Interesse der Gemeinschaft zuwiderläuft." $" 156$

„Die Kommission ist nicht davon überzeugt, dass der erforderliche Programmbezug der neuen Mediendienste (,programmbezogene“ und „programmbegleitende“ „Mediendienste“ bzw. „Telemedien“ im Rahmen des neuen Rundfunkstaatsvertrags) angemessen ist, um zu ermitteln, inwieweit neue Medienangebote, die über die bloße Verbreitung ähnlicher oder identischer Inhalte über verschiedene Plattformen hinausgehen, denselben demokratischen, sozialen und kulturellen Bedürfnissen dienen wie Fernsehprogramme im herkömmlichen Sinne.

Diesbezüglich stellt die Kommission fest, dass es keine allgemein anwendbaren Kriterien für die Bestimmung der Art des Programmbezugs gibt, anhand deren eindeutig ermittelt werden könnte, inwieweit die in Frage stehenden Online-Tätigkeiten dieser Vorgabe gerecht werden. Diesbezüglich erklärten die deutschen Behörden zwar, dass ein Programmbezug gegeben sei, wenn auf das Programmangebot unmittelbar Bezug genommen werde, wenn auf für Fernsehprogramme genutzte Quellen und Materialien zurückgegriffen und wenn die Fernsehprogramme thematisch und inhaltlich die Programmaufgaben unterstüt- 
zen, vertiefen und begleiten. Allerdings sind diese Umstände nicht verbindlich festgelegt, so dass keine angemessene Kontrolle gewährleistet ist. ${ }^{157}$ In diesem Zusammenhang stellt die Kommission auch fest, dass die KEF wiederholt erklärt hat, dass sie nicht in der Lage gewesen sei zu beurteilen, ob die Online-Angebote von ARD und ZDF tatsächlich programmbezogen und programmbegleitend waren." 158

Je weniger der flexibilisierte Auftrag ${ }^{159}$ mithin verbindlich festgelegt ist und hierdurch eine angemessene Kontrolle der Einhaltung seiner Grenzen ermöglicht, um so höher ist das Risiko, dass das Kriterium der Auftragsdefinition zur Anwendbarkeit des Art. 106 Abs. 2 AEUV aus Sicht der Kommission nicht erfüllt ist. Das Risiko erhöht sich zusätzlich, wenn die KEF oder ein in vergleichbarer Weise zur Kontrolle berufenes unabhängiges Gremium gegenüber der Kommission oder in sonstiger Weise Defizite in der Kontrollfähigkeit auf der Grundlage des materiellen und/oder prozeduralen Rundfunkrechts betont.

\section{b) Beauftragung und Kontrolle}

Auch im Hinblick auf die erforderliche Beauftragung besteht im Lichte der geplanten Flexibilisierung ein Risikopotential, dessen sich die Länder bei der Fortentwicklung des Rahmens bewusst sein müssen, in dem sich eine etwaige zukünftige vollindexierte Beitragsfinanzierung des öffentlich-rechtliche Rundfunks bewegt. Denn hier enthalten voraussichtlich folgende Bedenken der Kommission ${ }^{160}$ fortdauernd prüfungsrelevante Ansätze:

- Die Kommission ist der Auffassung, ,dass eine bloße Ermächtigung einer öffentlichrechtlichen Rundfunkanstalt zur Erbringung von Tätigkeiten, deren Umfang nicht hinreichend präzise bestimmt ist, nicht als ausreichende Beauftragung angesehen werden kann“. Diese den Anstalten eingeräumte allgemein gehaltene Möglichkeit müsste näher ausgestaltet werden, und die öffentlich-rechtliche Rundfunkanstalt müsste eigens mit der Erbringung der so konkretisierten Dienste beauftragt werden.

- Insbesondere kann aus Sicht der Kommission eine eingehendere Beschreibung von geplanten Angeboten in „Selbstverpflichtungen der öffentlich-rechtlichen Rundfunkanstalten ... nicht als förmliche Rechtshandlung zur Übertragung des öffentlichen Auftrags angesehen werden, da sie von den öffentlich-rechtlichen Rundfunkanstalten selbst verfasst wurde“. Ein bloßer staatsvertraglicher Hinweis auf Schwerpunkte der Angebote in den Bereichen Information, Bildung und Kultur ist aus Sicht der Kommission nicht ausreichend präzise.

157 Hervorhebung d. Verfassers.

158 Europäische Kommission (2007), Tz. $234 \mathrm{f}$.

159 Die geplante Profilschärfung stellt im Übrigen erkennbar keinen „offensichtlichen Fehler“ bei der Auftragsdefinition dar; weitergehende Einschätzungen sind derzeit mangels Kenntnis der Auftragsdefinition nicht möglich.

160 Europäische Kommission (2007), Tz. 247 ff. 
- Die Kommission vertritt die Auffassung, dass die Staatsferne eine Ausweitung des Auftrags der öffentlich-rechtlichen Rundfunkanstalten ohne klare Bestimmung der neuen Angebote durch die Länder nicht rechtfertigen kann. „Die Kommission hält es nicht für akzeptabel, dass es im Rahmen der derzeitigen Finanzierungsregelung ausschließlich den öffentlich-rechtlichen Rundfunkanstalten einschließlich ihrer internen Aufsichtsgremien überlassen bleibt, den Umfang ihrer Tätigkeiten festzulegen. Die Frage der Beauftragung ist von der Frage der redaktionellen Unabhängigkeit zu trennen, die durch das Erfordernis der Beauftragung nicht in Frage gestellt wird. Es obliegt in der Tat den Rundfunkanstalten, im Rahmen des öffentlichen Auftrags auf der Grundlage publizistischer Kriterien über den Inhalt der einzelnen Programme und der neuen Medienangebote zu entscheiden.“

Vor diesem Hintergrund erscheint eine Flexibilisierung der Beauftragung, die zugleich die Erfordernisse des Beihilfenkompromisses beachtet, außerordentlich ambitioniert. Eine Flexibilisierung, die in Bezug auf zusätzliche Möglichkeiten inhaltlicher Präsentation des öffentlich-rechtlichen Rundfunks in Form neuer Angebote auf einen Akt der Billigung entsprechender Angebotskonzepte seitens des öffentlich-rechtlichen Rundfunks durch die Länder verzichten würde, wäre mit einem hohen Risiko des beihilfeaufsichtlichen Einschreitens der Kommission verbunden. Gleiches gilt für einen Flexibilisierungsansatz, der ausschließlich auf Selbstverpflichtung seitens der ARD-Anstalten, des ZDF und/oder des Deutschlandradio in Bezug auf die geplante Schärfung des öffentlich-rechtlichen Profils setzen würde, sofern dieses mit einem Abbau bisheriger staatsvertraglicher Auftragsklauseln in den $\S \S 11 \mathrm{ff}$. RStV verbunden wäre.

Die Kommission betonte im Übrigen in ihrer Entscheidung aus 2007, dass die bestehenden Kontrollmechanismen in Bezug auf die Wahrung des Auftrags - neben interner Kontrolle durch die Gremien der öffentlich-rechtlichen Rundfunkanstalten eine externe Kontrolle, die zum einen durch die Länderparlamente auf der Grundlage der Berichte über die finanzielle Lage der Rundfunkanstalten und zum anderen durch die Länder in Ausübung ihrer Rechtsaufsicht wahrgenommen wird - „,nur dann wirklich wirksam funktionieren, wenn der öffentliche Auftrag hinreichend klar und genau bestimmt ist" ${ }^{\text {“ }}{ }^{161}$

\section{c) Verhältnismäßigkeit}

Im Hinblick auf das Prüfkriterium der Verhältnismäßigkeit bei der Frage der Anwendbarkeit des Art. 106 Abs. 2 AEUV berücksichtigte die Kommission in ihrer Entscheidung folgende Gesichtspunkte: „(1) getrennte Buchführung, (2) Kontrolle der Beschränkung der staatlichen Finanzierung auf die Nettokosten des öffentlichen Auftrags und (3) Prüfung möglicher Wettbewerbsverfälschungen, die nicht durch die Erfüllung des öffentlich-rechtlichen Auftrags bedingt sind“. ${ }^{162}$ 
Während ein Übergang zu einer Vollindexierung voraussichtlich keine Auswirkungen auf den Umfang getrennter Buchführung haben dürfte, wie er in Umsetzung des Beihilfekompromisses ${ }^{163}$ durch $\S 16$ a Abs. 1 Satz 4, 5 RStV festgelegt wurde, und auch die klare und ausdrückliche Verpflichtung der Rundfunkanstalten zu marktkonformen Verhalten in $\S 16 a$ Abs. 1 Satz 3 und Abs. 2 RStV sowie die diesbezüglichen Kontrollrechte der KEF und der Rechnungshöfe nach $\S 16 \mathrm{~d}$ RStV beim Übergang fortbestehen dürften, ${ }^{164}$ birgt ein solcher Übergang deutliches Risikopotential in Bezug auf die Beschränkung der Ausgleichsleistungen auf die Nettokosten des öffentlichen Auftrags. Dieses besteht namentlich in Bezug auf die geforderte Ex-post-Kontrolle einer möglichen Überkompensation. Hierzu hatte die Kommission 2007 ausgeführt: ${ }^{165}$

„Entsprechend ihrer bisherigen Entscheidungspraxis ist die Kommission der Auffassung, dass die relevanten Rechtsakte eindeutige Bestimmungen dahingehend enthalten sollten, dass die jährlich bereitgestellten öffentlichen Finanzmittel auf die Nettokosten für die Erbringung des öffentlichen Auftrags in einem jeden Haushaltsjahr zu begrenzen sind, sowie angemessene Kontrollmechanismen vorsehen sollten, die gewährleisten, dass die Rundfunkanstalten nur die zur Deckung der Kosten des öffentlichen Auftrags erforderlichen Finanzmittel erhalten. Die Kontrollmechanismen müssen sicherstellen, dass in der Regel eventuelle Überschüsse den Rundfunkanstalten nicht zur freien Verfügung stehen. Sofern die Ermittlung des Finanzbedarfs sowie die Gewährung des Ausgleichs jährlich erfolgen, sind eventuell am Jahresende verbuchte Überschüsse zurückzufordern oder von den Zahlungen für das folgende Haushaltsjahr abzuziehen. Die Kommission hat jedoch eine Marge von $10 \%$ zugelassen, um die Rundfunkanstalten in die Lage zu versetzen, auf Mehrkosten bzw. Mindereinnahmen zu reagieren. Andererseits können eventuell am Jahresende verbuchte Überschüsse unter bestimmten Voraussetzungen dann bei den Rundfunkanstalten verbleiben und auf das nächste Haushaltsjahr übertragen werden, wenn die Finanzierungsregelung Zuwendungen für einen längeren Zeitraum festlegt. In beiden Fällen müssen jedoch die am Ende eines bestimmten Zeitraums verbuchten Überschüsse der Rundfunkanstalt endgültig entzogen werden.“

Offen - und insoweit risikogeneigt - ist beim derzeitigen Stand der Diskussion über eine „Vollindexierung“ insbesondere, welches Schicksal $\S 1$ Abs. 4 und $\S 3$ Abs. 2 Rundfunkfinanzierungsstaatsvertrag haben werden, die in Umsetzung des Beihilfekompromisses $^{166}$ vorsehen, dass

- „(falls) die Gesamterträge der in der ARD zusammengeschlossenen Landesrundfunkanstalten, des ZDF oder des Deutschlandradios die Gesamtaufwendungen für die Erfüllung ihres Auftrages (übersteigen),... diese Beträge verzinslich anzulegen und bei zehn vom

163 A.a.O., Tz. $375 \mathrm{f}$.

164 Vgl. zu den entsprechenden Zusagen Deutschlands im Beihilfekompromiss a.a.O., Tz. 389 ff.

165 A.a.O., Tz. 281.

166 A.a.O., Tz. 384. 
Hundert der jährlichen Beitragseinnahmen übersteigende Beträge als Rücklage zu bilden (sind) $)^{\text {; }}$;

- „(die KEF) bei der Prüfung und Ermittlung des Finanzbedarfs ... sämtliche Erträge der Rundfunkanstalten (berücksichtigt). Die Gesamterträge der Rundfunkanstalten aus Beiträgen und weiteren direkten oder indirekten Einnahmen sollen die zur Erfüllung des öffentlichen Auftrags notwendigen Ausgaben und Aufwendungen decken. Überschüsse am Ende der Beitragsperiode werden vom Finanzbedarf für die folgende Beitragsperiode abgezogen. Die Übertragung von Defiziten ist nicht zulässig.“

Die Kommission hatte $2007^{167}$ anerkannt,

„dass ein System, das auf der Ermittlung des Finanzbedarfs der öffentlichen Rundfunkanstalten über einen Zeitraum von vier Jahren und der entsprechenden Bestimmung der Höhe der Gebühren durch ein unabhängiges Gremium beruht, dazu führen kann, dass einzelne Jahresabschlüsse eine Überkompensierung aufweisen. Übersteigen die Gebühreneinkünfte die Kosten des öffentlichen Auftrags am Ende eines Haushaltsjahres, müsste der Überschuss der Rundfunkanstalt nicht entzogen werden, sofern dieser dem Geldbetrag entspricht, der für andere Zwecke bestimmt war, deren Kosten planmäßig erst zu einem späteren Zeitpunkt des maßgeblichen Zeitraums anfallen werden. Unter bestimmten Umständen kann es gerechtfertigt sein, dass eine solche systembedingte Überkompensierung $10 \%$ der jährlichen Finanzmittel übersteigt. Vor dem Hintergrund, dass der in anderen Fällen zugestandene „Puffer” von 10 \% es den öffentlichen Rundfunkanbietern ermöglichen sollte, auf unvorhergesehene Mehrkosten und Mindereinnahmen zu reagieren, ist diese Obergrenze dann nicht unbedingt anwendbar, wenn wie im Falle Deutschlands der Überschuss in einem Haushaltsjahr das Ergebnis bereits vorhersehbarer Ereignisse bzw. Projekte ist, deren Finanzbedarf von einer unabhängigen Kontrollinstanz (in diesem Falle der KEF) ermittelt wurde."

Ob dieses Anerkenntnis einer systembedingt $10 \%$ der jährlichen Finanzmittel übersteigenden Überkompensation seitens der Kommission auch dann noch besteht, wenn die Überkompensation Ergebnis einer Vollindexierung und damit einer Auflösung der engen Verbindung von Auftragsdefinition und aufgabengerechter Finanzausstattung ist und wenn zugleich die Einwirkungsmöglichkeiten einer unabhängigen Kontrollinstanz wie der KEF zurückgenommen werden, erscheint äußerst fraglich.

\section{Zur Bedeutung der jüngeren Judikatur des EuGH}

\section{Zum Verhältnis von Art. 107 Abs. 1, Art. 106 AEUV und Amsterdamer Protokoll}

Der EuGH hat sich $2017^{168}$ grundlegend mit dem Verhältnis von Art. 107 Abs. 1 zu Art. 106 Abs. 2 AEUV unter Berücksichtigung des Amsterdamer Protokolls auseinanderge-

167 A.a.O., Tz. 385.

168 EuGH, Rs. C-660/15 P [2017] Viasat Broadcasting UK/Kommission [22-37]. 
setzt und dabei - aufbauend auf früherer Judikatur - festgehalten, dass eine staatliche Maßnahme nicht unter Art. 107 Abs. 1 AEUV fällt, soweit diese Maßnahme als Ausgleich anzusehen ist, der die Gegenleistung für Leistungen bildet, die von den Unternehmen, denen sie zugutekommt, zur Erfüllung gemeinwirtschaftlicher Verpflichtungen erbracht werden, so dass diese Unternehmen in Wirklichkeit keinen finanziellen Vorteil erhalten und die genannte Maßnahme somit nicht bewirkt, dass sie gegenüber den mit ihnen im Wettbewerb stehenden Unternehmen in eine günstigere Wettbewerbsstellung gelangen. Es müssen insoweit die vier Altmark-Trans-Voraussetzungen erfüllt sein, damit eine solche Maßnahme nicht als staatliche Beihilfe eingestuft wird. In dem Fall, dass diese Voraussetzungen nicht erfüllt wären, würde mit der fraglichen staatlichen Maßnahme dem Unternehmen, dem sie zugutekommt, ein selektiver Vorteil gewährt, und wenn außerdem die übrigen in Art. 107 Abs. 1 AEUV aufgestellten Kriterien erfüllt wären, würde diese Maßnahme eine grundsätzlich mit dem Binnenmarkt unvereinbare Beihilfe darstellen.

Bereits der Wortlaut von Art. 106 Abs. 2 AEUV zeige, dass Ausnahmen von den Vertragsvorschriften nur zulässig seien, wenn sie für die Erfüllung der einem Unternehmen, das mit einer Dienstleistung von allgemeinem wirtschaftlichem Interesse betraut ist, übertragenen besonderen Aufgabe erforderlich seien. Es genügt hierzu aus Sicht des EuGH, dass ohne die streitigen Rechte die Erfüllung der dem Unternehmen übertragenen besonderen Aufgaben gefährdet wäre oder dass die Beibehaltung dieser Rechte erforderlich ist, um ihrem Inhaber die Erfüllung seiner im allgemeinen wirtschaftlichen Interesse liegenden Aufgaben zu wirtschaftlich tragbaren Bedingungen zu ermöglichen.

Die Kommission hat bei der Prüfung einer Maßnahme nach Art. 106 Abs. 2 AEUV nicht zu prüfen, ob die in der Altmark-Rechtsprechung aufgestellten Voraussetzungen, insbesondere die zweite und die vierte Voraussetzung, eingehalten sind. Die Kontrolle, ob die in dieser Rechtsprechung aufgestellten Voraussetzungen eingehalten sind, ist vorgelagert, d.h., sie erfolgt bei der Prüfung, ob die fraglichen Maßnahmen als staatliche Beihilfen einzustufen sind. Diese Frage geht nämlich der gegebenenfalls durchzuführenden Überprüfung voraus, ob eine unvereinbare Beihilfe gleichwohl für die Erfüllung der Aufgabe, die dem durch die fragliche Maßnahme Begünstigen übertragen wurde, nach Art. 106 Abs. 2 AEUV erforderlich ist. Die in der Altmark-Rechtsprechung aufgestellten Voraussetzungen sind dagegen nicht mehr heranzuziehen, wenn die Kommission, nachdem sie festgestellt hat, dass eine Maßnahme als Beihilfe einzustufen ist, insbesondere, weil das begünstigte Unternehmen nicht den Vergleich mit einem durchschnittlichen, gut geführten Unternehmen, das so angemessen ausgestattet ist, dass es den gestellten gemeinwirtschaftlichen Anforderungen genügen kann, zu bestehen vermag, prüft, ob diese Beihilfe nach Art. 106 Abs. 2 AEUV gerechtfertigt werden kann. Diese Schlussfolgerung wird durch den Wortlaut des Protokolls Nr. 29 über den öffentlich-rechtlichen Rundfunk in den Mitgliedstaaten gestützt

Aus Sicht des EuGH kann zudem Art. 106 Abs. 2 AEUV, da er durch das Protokoll Nr. 26 über Dienste von allgemeinem Interesse und in dem vorliegend in Rede stehenden Bereich durch das Protokoll Nr. 29 über den öffentlich-rechtlichen Rundfunk in den Mitgliedstaaten näher erläutert wird, nicht isoliert allein im Hinblick auf ihren Wortlaut ohne 
Berücksichtigung der in diesen Protokollen vorgenommenen Klarstellungen ausgelegt werden.

\section{Zur Unionsrechtskonformität des deutschen Rundfunkbeitragssystems der Finanzierung des öffentlich-rechtlichen Rundfunks}

Der EuGH hat jüngst ${ }^{169}$ den Übergang von der Gebühren- zur Beitragsfinanzierung des öffentlich-rechtlichen Rundfunks in Deutschland ${ }^{170}$ als beihilfeaufsichtsrechtlich unbedenklich eingestuft; einen Bedarf zur Unterrichtung der EU-Kommission über diesen Systemwechsel in der Finanzierung auf der Grundlage des Art. 108 Abs. 3 AEUV sah der EuGH nicht. ${ }^{171}$ Zur Begründung führte er insbesondere aus, dass

- es unstreitig sei, dass der Übergang zu einem Rundfunkbeitragssystem nicht das Ziel der Finanzierungsregelung für den deutschen öffentlich-rechtlichen Rundfunk geändert hat, da der Rundfunkbeitrag weiterhin, wie die Rundfunkgebühr, an deren Stelle er getreten ist, der Finanzierung der öffentlichen Dienstleistung Rundfunk dient; ${ }^{172}$

- es ebenfalls unstreitig ist, dass der Kreis, der von dieser Regelung Begünstigten identisch ist mit dem der früheren Beihilfeempfänger;

- aus Sicht des EuGH nichts dafür spricht, dass der Wechsel zum Rundfunkbeitragssystem mit einer Änderung des öffentlichen Auftrags an die öffentlich-rechtlichen Sender oder der Tätigkeiten dieser Sender, die mit dem Rundfunkbeitrag subventioniert werden können, verbunden gewesen wäre.

Schließlich stellt der EuGH fest, dass der Rundfunkbeitragsstaatsvertrag den Entstehungsgrund für die öffentlich-rechtlich auferlegte Belastung geändert hat. Allerdings zielte diese Änderung zum einen im Wesentlichen darauf ab, die Voraussetzungen für die Erhebung des Rundfunkbeitrags vor dem Hintergrund der technologischen Entwicklung in Bezug auf den Empfang der Programme der öffentlich-rechtlichen Sender zu vereinfachen. Hierbei handelt es sich aus Sicht des EuGH offenbar um einen legitimen Zweck des Systemwechsels ohne unmittelbar hieraus sich ergebende Unterrichtungspflichten nach Art. 108 Abs. 3 AEUV. Zum anderen hat aus Sicht Verfahrensbeteiligter, der der EuGH nicht entgegentritt, die Ersetzung der Rundfunkgebühr durch den Rundfunkbeitrag zu keiner wesentlichen Er-

169 EuGH Rs. C-492/17 [2018] Rittinger u.a. [53-67].

170 Vgl. zu diesem Übergang auch Wagner (2011), S. 234 ff.

171 An dieser Rechtsprechungslinie dürfte sich in dem nunmehr durch das BVerwG eingeleiteten Vorabentscheidungsverfahren nichts ändern. Dieses betrifft nicht die Beitragsfinanzierung als solche, sondern Fragen der Abwicklung der Beitragspflicht. Vgl. hierzu die Pressemitteilung Nr. 23/209 des BVerwG vom 28. März 2019, abrufbar unter https://www.bverwg.de/pm/2019/23.

172 Insoweit betont der EuGH konsequenterweise auf der Grundlage des unionsrechtlichen Prüfungsmaßstabs die Qualität von öffentlich-rechtlichem Rundfunk als Dienstleistung, während Ausgangspunkt der grundrechtlichen Erwägungen des Bundesverfassungsgerichts in seinem Rundfunkbeitrags-Urteil vom 18.7.2018 (ECLI:DE:BVerfG:2018:rs20180718.1bvr167516) der individuelle Nutzen dieser Dienstleistung war; vgl. zu dieser Entscheidung Ukrow (2018), S. 2 ff. 
höhung der Vergütung geführt, die die öffentlich-rechtlichen Sender erhalten, um die Kosten zu decken, die mit der Erfüllung ihres öffentlichen Auftrags verbunden sind.

Mit dieser Haltung hat der EuGH in der in Deutschland zuvor bestehenden Kontroverse zur Vereinbarkeit der Finanzierung des öffentlich-rechtlichen Rundfunks mit dem Beihilfeaufsichtsregime der EU im Allgemeinen und zur beihilferechtlichen Relevanz des Systemwechsels von der Gebühren- zur Beitragsfinanzierung im Besonderen klar Stellung bezogen. ${ }^{173}$ Eine über diesen Systemwechsel hinausreichende Bedeutung auch für eine zukünftige beihilferechtliche Unbedenklichkeit eines Wechsels zu einer Vollindexierung lässt sich der Entscheidung des EuGH indessen nicht abschließend entnehmen:

- Zwar würde auch mit einem solchen Wechsel das Ziel der Finanzierungsregelung für den öffentlich-rechtlichen Rundfunk in Deutschland nicht beihilfeaufsichtsrechtlich relevant geändert, da der Rundfunkbeitrag weiterhin der Finanzierung der öffentlichen Dienstleistung Rundfunk dienen würde. Nebenziele des Übergangs zur Vollindexierung wie die Vermeidung von kontroversen Debatten über das Erfordernis einer etwaigen Erhöhung des Rundfunkbeitrags im Lichte des bisherigen Beitragsfestsetzungsverfahrens oder eine größere Beitragsstabilität auf der Zeitachse wären insoweit ohne Bedeutung.

- Ferner wäre auch bei einem Übergang zur Vollindexierung der Kreis, der von dieser Regelung begünstigten Rundfunkanstalten identisch mit dem der bisherigen Beihilfeempfänger. Hieran würde sich auf den ersten Blick auch nichts ändern, wenn im Gefolge dieses Systemwandels kleinere und mittlere Rundfunkanstalten oder die Landesmedienanstalten, die durch die jüngste Rundfunkbeitragsentscheidung des BVerfG verfassungsdogmatisch als Teil des öffentlich-rechtlichen Rundfunks eingeordnet wurde, ${ }^{174}$ oder einzelne von diesen, nicht mehr bedarfsgerecht finanziert würden. Denn das Beihilfeaufsichtsrecht der EU enthält grundsätzlich keine unionsrechtliche Pflicht zu mitgliedstaatlicher Beihilfegewährung. Allerdings könnte eine entsprechende Unterfinanzierung in einer ggf. auch beihilfeaufsichtsrechtlich bedeutsamen Weise die Kohärenz der Finanzierung der Gesamtveranstaltung öffentlich-rechtlicher Rundfunk in Frage stellen.

- Jenseits dieser beihilfeaufsichtsrechtlichen Fragestellungen an der Schnittstelle von unionsrechtlichem Kohärenzgebot und verfassungsrechtlichem bündischem Solidaritätsgebot erweist sich allerdings als nennenswerter Risikofaktor bei einem Umstieg zur Vollindexierung, dass sich diese Überlegung in ein medienpolitisches Gesamtreformprojekt einfügt, das auch die Frage der Auftragsdefinition unter dem Blickwinkel der Beitragsstabilität im Blick hat. Während der Wechsel zum Rundfunkbeitragssystem wie gesehen auch deshalb beihilfeaufsichtsrechtlich unbedenklich war, weil er nicht mit einer Änderung des öffentlichen Auftrags an die öffentlich-rechtlichen Rundfunkanstalten oder der Tätigkeiten dieser Anstalten, die mit dem Rundfunkbeitrag subventioniert werden kön-

173 Vgl. zu dieser Kontroverse z.B. Bartosch (2016), S. 340 ff.; Gundel, ZUM 2008, 758 (759 ff.); Krone (2010), S. 59 ff.; Smith (2010).

174 Vgl. BVerfG, Urteil des Ersten Senats vom 18. Juli 2018 - 1 BvR 1675/16 - Rn. 83 f.; zu dieser Einordnung vgl. auch Ukrow (2018), S. 8 f. 
nen, verbunden gewesen war, kann ein solcher Zusammenhang im Blick auf den sich aus dem Protokoll der jüngsten Ministerpräsidentenkonferenz ergebenden Diskussionsstand im Länderkreis nicht ausgeschlossen werden. Die zeitliche Verkopplung von Auftrags- und Finanzierungsdiskussion erweist sich damit nicht nur als verfassungs-, sondern auch als unionsrechtlicher Risikofaktor. ${ }^{175} \mathrm{Ihm}$ könnte durch eine hinreichend weite terminliche Entzerrung der beiden Reformdiskussionen zu Auftrag und Finanzierung Rechnung getragen werden.

Risiken bestehen dabei im Übrigen nicht nur in inhaltlicher, sondern auch in prozeduraler Hinsicht. Denn die Entscheidung des EuGH legt nahe, dass für den Fall einer Änderung des öffentlich-rechtlichen Auftrags eine neuerliche Prüfung der Europarechtskonformität des Beitragssystems durch die Kommission auf der Grundlage einer Unterrichtung nach Art. 108 Abs. 3 AEUV angezeigt ist. Ein solches prozedurales Risiko, dass im Hinblick auf einen Übergang von der Einordnung der Rundfunkfinanzierung als beihilferechtlicher Besitzstand zu einer Einordnung als neue Beihilfe verbunden wäre, besteht im Übrigen auch mit Blick auf eine weitere Passage des Urteils des EuGH: Aus Sicht des EuGH war im Vorabentscheidungsverfahren ,nicht dargetan worden, dass das Rundfunkbeitragsgesetz eine wesentliche Änderung der Regelung zur Finanzierung des öffentlich-rechtlichen Rundfunks in Deutschland mit sich gebracht hätte, die es erforderlich machte, die Kommission gemäß Art. 108 Abs. 3 AEUV von seinem Erlass zu unterrichten“. ${ }^{176}$ Ob auch einem Übergang zu einer „Vollindexierung“, bei der keine hinreichenden Absicherungen gegen eine Finanzierung vorhanden sind, die das Funktionserforderliche nennenswert überschreitet, als nicht „wesentliche“ Änderung i.S. dieses Urteils eingestuft werden kann, erscheint fraglich.

\section{Ein kurzer Ausblick}

Die aufgezeigten unionsrechtlichen Risiken könnten, gerade im Jahr einer Neuwahl des Europäischen Parlaments und einer Neukonstituierung der Europäischen Kommission Grund sein, die Tragweite des Subsidiaritätsprinzips neu zu entdecken sowie das Verhältnis zwischen europäischem Wettbewerbsrecht und nationalem Rundfunkfinanzierungsrecht neu zu justieren.

So sinnvoll es ist, dass sich die Europäische Kommission als Hüter transatlantischer Wettbewerbsoffenheit gerade auch im Verhältnis zu den „GAFA“ (Google, Apple, Facebook, Amazon) als neuen, die internationale Kommunikationsordnung zunehmend zumindest potentiell vielfaltsverengend gestaltenden Medienakteuren annimmt, so wenig sinnhaft erscheint eine mitgliedstaatliche Souveränitätsrechte belastende unionsrechtliche Kontrolle einer mitgliedstaatlichen Medienregulierung, die für die Gewährleistung eines freien, inte-

175 Ein solches Risiko zeitlicher Verkoppelung hat sich jüngst bei der Frage mittelbarer Diskriminierung durch die Einführung einer PKW-Maut in Deutschland realisiert; vgl. EuGH Rs. C-591/17 [2019] Österreich/Deutschland [37-78].

176 EuGH Rs. C-492/17 [2018] Rittinger u.a. [66]. 
grationsförderlichen Diskurses schlechthin konstituierend ist. Dass sich die Europäische Kommission den GAFAs regulatorisch zuwendet, ist nicht zuletzt deshalb sinnvoll, weil die für die Vielfaltssicherung innerstaatlich berufenen Akteure insoweit jenseits einer Risikoanalyse (noch?) nicht zu effektiven Schutzvorkehrungen in einem globalisierten und digitalisierten Rundfunksystem verständigen konnten - und weil ein Nebeneinander mitgliedstaatlicher Regulierungsansätze insoweit als Einstieg in eine Regulierungsdiskussion hilfreich, aber nicht abschließend zielführend sein kann.

Die sinnvollen innerstaatlichen Debatten zur Zukunft des öffentlich-rechtlichen Rundfunks in Auftrag und Finanzierung in Anbetracht neuer gesellschaftlicher, publizistischer, technologischer und kommunikationsbezogener Herausforderungen sollten demgegenüber fokussierter als bislang auf der hierfür verfassungsrechtlich bestimmten Ebene - in Deutschland derjenigen der Länder - geführt werden - dort allerdings stärker als bislang auch interparlamentarisch. Ein Modell, dass Staatsverträge der Länder ohne hinreichende Rückkopplung in die Parlamente hinein abgeschlossen werden, gefährdet mit der damit verbundenen Transparenzschwäche die demokratische Legitimation des öffentlich-rechtlichen Rundfunks. Die insoweit gebotene Debatte droht dabei durch ein extensives Verständnis wettbewerbsrechtlicher Aufsicht seitens der Organe der EU - auch in einer über den Rundfunkfinanzierungsanlass hinausreichenden Weise - nicht begünstigt, sondern belastet zu werden.

Der neue Kommissionspräsident - oder eine Präsidentin - wird durch das neu gewählte Europäische Parlament gewählt. ${ }^{177}$ Die EU-Mitgliedstaaten schlagen zwar die weiteren Mitglieder der Europäischen Kommission vor; diese Kommissare - einschließlich derjenigen, die für Medien und für Beihilfeaufsicht politisch federführend sind - bedürfen aber einer Bestätigung durch das Europäische Parlament. Kein Kommissar, keine Kommissarin kann gegen den mehrheitlichen Willen des Europäischen Parlaments Mitglied der EUKommission werden. Kandidatinen und Kandidaten müssen sich in einer Anhörung den Fragen der Europaabgeordneten stellen. Niemand hindert deutsche Abgeordnete daran, bei solchen Fragen zumindest inzident für eine stärkere Berücksichtigung mitgliedstaatlicher Souveränitätsrechte an der Schnittstelle von Beihilfeaufsicht und Finanzregulierung für einen unabhängigen öffentlich-rechtlichen Rundfunk zu werben.

177 Der Kandidat/Die Kandidatin wird zuvor vom Europäischen Rat gemäß Art. 17 Abs. 7 EUV vorgeschlagen, wobei dieser das Ergebnis der Parlamentswahlen berücksichtigen muss, hieran aber nicht rechtlich gebunden ist. 


\section{Literatur}

ARD (2018), Bericht über die wirtschaftliche und finanzielle Lage der Landesrundfunkanstalten. Abgerufen von http://www.ard.de/download/1015988/Bericht.pdf

Badura, P. (1996), Gewährleistung der Freiheit des Rundfunks, „Funktion“ des Rundfunks und „öffentliche Aufgabe“ der Rundfunkveranstalter, in: Merten, D. u.a. (Hrsg.), Der Verwaltungsstaat im Wandel. Festschrift für Franz Knöpfle, 1-9

Bartosch, A. (2016), EU-Beihilfenrecht, 2. Auflage

Bellucci, L. (2010), National Support for Film Production in the EU, European Law Journal 16 (2), 211-232

Berggreen-Merkel, I. (1995), Die rechtlichen Aspekte der Kulturpolitik nach dem Maastrichter Vertrag

Birnstiel, A., Bungenberg, M. \& Heinrich, H. (Hrsg.) (2013), Europäisches Beihilfenrecht

Breuer, L. (2013), Das EU-Kartellrecht im Kraftfeld der Unionsziele.

Brinkmann, T. (2013), Zur Aktualität des Vielfaltgebots in den Massenmedien, Zeitschrift für Urheberund Medienrecht 57 (3), 193-201

Burggraf, J. \& Wiesner, J. (2019), Der Brexit aus Sicht der europäischen Medienregulierung, Media Perspektiven, 50 (2), 34-43

Calliess, C. \& Ruffert, M. (Hrsg.) (2016), EUV/AEUV, 5. Auflage

Cappello, M. (Hrsg.) (2015), Online-Aktivitäten öffentlich-rechtlicher Medien: Auftrag und Finanzierung, IRIS Spezial 2015-1

Cole, M., Oster., J. (2017), Zur Frage der Beteiligung privater Rundfunkveranstalter in Deutschland an einer staatlich veranlassten Finanzierung. Abgerufen von https://www.prosiebensat1.com/uploads/ 2017/07/03/P7S1_RundfunkfinanzierungBeitrag_Gutachten.pdf

Cole, M., Ukrow, J. \& Etteldorf, C. (2018), Audiovisual Sector and Brexit: the Regulatory Environment, Abgerufen von: http://www.europarl.europa.eu/RegData/etudes/STUD/2018/629177/IPOL_ STU(2018)629177_EN.pdf

Cornils, M. (2019), Verfassungs- und unionsrechtliche Rahmenbedingungen einer Vollindexierung des Rundfunkbeitrag. Abgerufen von: https://www.mainzer-medieninstitut.de/wp-content/uploads/Gut achten-Indexierung-Endfassung_Publikation.docx.pdf

Council of Europe (2019), Democracy at Risk: Threats and Attacks against Media Freeedom in Europe. Annual Report 2019 by the Partner Organisations to the Council of Europe Platform to Promote the Protection of Journalism and Safety of Journalists. Abgerufen von https://rm.coe.int/annu al-report-2018-democracy-in-danger-threats-and-attacks-media-freed/1680926453

Dauses, M. \& Ludwigs, M. (Hrsg.) (2019), Handbuch des EU-Wirtschaftsrechts

de Witte, B. (1995), The Cultural Dimension of Community Law, in: Academy of European Law (Hrsg.), Collected Courses of the Academy of European Law, Vol. IV/1, 229-299

Dieterich, P. (2014), Systemgerechtigkeit und Kohärenz

Dörr, D., Holznagel, B. \& Picot, A. (2016), Legitimation und Auftrag des öffentlich-rechtlichen Fernsehens in Zeiten der Cloud, Zeitschrift für Urheber- und Medienrecht 60 (11), 920-947

Drexl, J. (2017), Bedrohung der Meinungsvielfalt durch Algorithmen, Zeitschrift für Urheber- und Medienrecht 61 (7), 529-543

Eberle, C.-E. (1993), Das Fernsehen im Zugriff des europäischen Rechts, in: Becker, B. u.a. (Hrsg.), Festschrift für Werner Thieme, 939-961

Elixmann, J. (2016), Rundfunkanstalten im Internet

Engel, D. (2015), Der Beitritt der Europäischen Union zur EMRK

Europäische Kommission (2007), Entscheidung vom 24.4.2007 - Staatliche Beihilfe E 3/2005 (ex- CP 2/2003, CP 232/2002, CP 43/2003, CP 243/2004 und CP 195/2004) - Deutschland. Die Finanzierung der öffentlich-rechtlichen Rundfunkanstalten in Deutschland (K [2007] 1761 endg.). Abgerufen von: https://www.ard.de/download/74354/index.pdf 
Europäische Kommission (2009), Mitteilung der Kommission über die Anwendung der Vorschriften über staatliche Beihilfen auf den öffentlich-rechtlichen Rundfunk, ABl. EU 2009 Nr. C 257/1

Ferreau, J. (2017), Öffentlich-rechtlicher Rundfunk und ökonomischer Wettbewerb

Frenz, W. (2007), Handbuch Europarecht. Band 3: Beihilfe- und Vergaberecht

Frenz, W. (2010), Handbuch Europarecht. Band 5: Wirkungen und Rechtsschutz

Frenz, W. (2012), Kohärente und systematische nationale Normgebung - nicht nur im Glücksspielrecht, Europarecht 47 (3), 344-354

Geiger, R., Khan, D,-E. \& Kotzur, M. (2017), EUV/AEUV, 6. Auflage

Germelmann, C. (2013), Kultur und staatliches Handeln

Grabitz, E., Hilf, M. \& Nettesheim, M. (Hrsg.) (2018), Das Recht der Europäischen Union

Gundel, J. (2002), Staatliche Ausgleichszahlungen für Dienstleistungen von allgemeinem wirtschaftlichen Interesse, Recht der Internationalen Wirtschaft 48 (3), 222-230

Gundel, J. (2008), Nationale Rundfunkfinanzierung, Art. 86 EGV und das EG-Beihilfenrecht: Die Position der Gemeinschaftsgerichte, Zeitschrift für Urheber- und Medienrecht 52 (10), S. 758-765

Hahn, C. (2010), Die Aufsicht des öffentlich-rechtlichen Rundfunks

Hain, K.-E. (2008), Die zweite Gebührenentscheidung des Bundesverfassungsgerichts - Kontinuität in den Zeiten der Konvergenz, JuristenZeitung 63 (3), 128-135

Haratsch, A. (2006), Die Solange-Rechtsprechung des Europäischen Gerichtshofs für Menschenrechte, Zeitschrift für ausländisches öffentliches Recht und Völkerrecht 66 (4), 927-947

Hartmann, B. (2014), Kohärenz im Glücksspielrecht: vertikal - horizontal - intersektoral, Europäische Zeitschrift für Wirtschaftsrecht 25 (21), 814-819

Hirsch, G. (1996), Europäischer Gerichtshof und Bundesverfassungsgericht - Kooperation oder Konfrontation, Neue Juristische Wochenschrift 49 (38), 2457-2466

Hirschle, T. (2019), Kurzgutachten zur Indexierung des Rundfunkbeitrags. Abgerufen von: https://ww w.vau.net/system/files/documents/kurzgutachten_zur_indexierung_des_rundfunkbeitrags.pdf

Hoff, B.-I. (2017), Das gute Öffentliche - das öffentliche Gut. Abgerufen von: https://www.medienpoli tik.net/2017/09/rundfunk-das-gute-oeffentliche-das-oeffentliche-gut/

Hoffmann, A. (2016), Der Rundfunkbeitrag

Hoffmann-Riem, W. (1991), Indexierung der Rundfunkgebühr in einem Experimentaldesign? in: ders. (Hrsg.), Die Indexierung der Rundfunkgebühr, 199-211

Immenga, U. \& Mestmäcker, E.-J. (2014), Europäisches Wettbewerbsrecht, 3. Auflage

Immenga, U. \& Mestmäcker, E.-J. (Hrsg.) (2016), Wettbewerbsrecht. Band 3: Beihilfen und Sonderbereiche, 5. Auflage

Jung, M. (2018), Die Europäisierung des Gemeinwohls am Beispiel des Art. 106 Abs. 2 AEUV

Jungheim, S. (2012), Medienordnung und Wettbewerbsrecht im Zeitalter der Digitalisierung und Globalisierung

Knodel, A. (2018), Medien und Europa

Knothe, M. \& Schwalba, M. (1999), Gebührenperiodenübergreifende Rücklagen als Finanzierungsbasis für Entwicklungsvorhaben des öffentlich-rechtlichen Rundfunks, Zeitschrift für Urheber- und Medienrecht 43 (6), 459-471

Kommission der EG (2001), Mitteilung über die Anwendung der Vorschriften über staatliche Beihilfen auf den öffentlich-rechtlichen Rundfunk (2001/C 320/04), ABl. EG 2001 Nr. C 320/5

Korte, S. (2016), Standortfaktor Öffentliches Recht

Krajewski, M. (2011), Grundstrukturen des Rechts öffentlicher Dienstleistungen

Krone, D. (2010), Gebührenfinanzierter Rundfunk und Beihilferecht

Kruse, E. (1996), Das gemeinschaftsrechtliche Beihilfenverbot und die für „Kultur“ und „kulturelles Erbe“ bestehende Befreiungsmöglichkeit, Europäisches Wirtschafts- und Steuerrecht, 4 (4), $113-119$ 
Künzler, M., Puppis, M., Schweizer, C. \& Studer, S. (2013),

Regulierungs-Monitoring 2012/2013. Monitoring-Report «Finanzierung des öffentlichen Rundfunks». Abgerufen von: https://www.researchgate.net/publication/280703329_Monitoring_Report_Finanzi erung_des_offentlichen_Rundfunks

Lane, R. (1993), New Community Competences under the Maastricht Treaty, Common Market Law Review 30 (5), 939-979

Langbauer, M. \& Ripel, S. (2015), Der öffentlich-rechtliche Rundfunk - ein Auslaufmodell?, Multimedia und Recht, 18 (9), 572-576

Lennartz, J. (2019), KEF-Anmeldung ist die wesentliche Weichenstellung. Abgerufen von: https://ww w.medienpolitik.net/2019/03/kef-anmeldung-ist-die-wesentliche-weichenstellung/

Lichtenegger, M. (2014), Verwertungsgesellschaften, Kartellverbot und Neue Medien

Lilienthal, V. (Hrsg.) (2009), Professionalisierung der Medienaufsicht. Neue Aufgaben für Rundfunkräte

Lippert, A. (2012), Das Kohärenzerfordernis des EuGH, Europarecht 47 (1), $90-99$

Lutzhöft, N. (2012), Eine objektiv-rechtliche Gewährleistung der Rundfunkfreiheit in der Europäischen Union?

Melcher, M. (2016), Dienstleistungen von allgemeinem wirtschaftlichem Interesse im europäischen Privatrecht

Mestmäcker, E.-J. \& Schweitzer, H. (2014), Europäisches Wettbewerbsrecht, 3. Auflage

Michl, W. (2016), Das Kohärenzkriterium in der Rechtsprechung des Europäischen Gerichtshofs, Zeitschrift für Wett- und Glücksspielrecht, 11 (2), 110-115

Mielke, J. (2019), Indexierung nur zusammen mit Flexibilisierung denken. Abgerufen von: https://ww w.medienpolitik.net/2019/03/indexierung-nur-zusammen-mit-flexibilisierung-denken/

Milker, J. (2017), »Social-Bots« im Meinungskampf, Zeitschrift für Urheber- und Medienrecht 61 (3), 216-222

Montag, F. \& Säcker, F. (Hrsg.) (2011), Münchener Kommentar zum Europäischen und Deutschen Wettbewerbsrecht (Kartellrecht) - Band 3: Beihilfen- und Vergaberecht

Müller, T. (2014), Wettbewerb und Unionsverfassung

Nettesheim, M. (2002), Europäische Beihilfeaufsicht und mitgliedstaatliche Daseinsvorsorge, Europäisches Wirtschafts- und Steuerrecht 13 (6), 253-263

Nickel, B. (2006), Indexierung der Rundfunkgebühr, Zeitschrift für Urheber- und Medienrecht 50 (10), 737-746

Nunner, M. (2009), Kooperation internationaler Gerichte

Oster, J. (2017), European and International Media Law

Perten, V. (2014), Rundfunkfinanzierung in Europa

Psychogiopoulou, E. (2008), Integration of Cultural Considerations in EU Law and Policies

Rabe, H.-J. (2006), Grenzen gemeinschaftsweiter Lizenzierung durch das Territorialitätsprinzip des Internationalen Urheberrechts, in: Riesenhuber, K. (Hrsg.), Wahrnehmungsrecht in Polen, Deutschland und Europa, 174-192

Ress, G. (1991), Kultur und Europäischer Binnenmarkt

Ress, G. (1995), Die Zulässigkeit von Kulturbeihilfen in der Europäischen Union, in: Randelzhofer, E. u.a. (Hrsg.), Gedächtnisschrift. für Eberhard Grabitz, 595-629

Ritlewski, K. (2009), Pluralismus als Strukturprinzip im Rundfunk, 2009

Robra, R. (2018), Keine Entpolitisierung der Rundfunkgesetzgebung. Abgerufen von: https://www.me dienpolitik.net/2018/09/rundfunk-keine-entpolitisierung-der-rundfunkgesetzgebung/

Schladebach, M. \& Simantiras, N. (2011), Grundfragen des unionalen Rundfunkrechts, Europarecht 46 (6) $784-807$ 
Schliesky, U. (2004), Souveränität und Legitimität von Herrschaftsgewalt

Schuster, U. (2017), Das Kohärenzprinzip in der Europäischen Union

Schwartz, I. (1993), Subsidiarität und EG-Kompetenzen. Der neue Titel „Kultur“. Medienvielfalt und Binnenmarkt, Archiv für Presserecht 25, 409-421

Schwarze, J. (2003), Urheberrechte und deren Verwaltung im Lichte des europäischen Wettbewerbsrechts, Zeitschrift für Urheber- und Medienrecht, 47 (1), 15-26

Smith, A. (2010), Das System der deutschen Rundfunkgebühr

Streinz, R. (2013), Das Kohärenzgebot in der Rechtsprechung des EuGH als Vorgabe für das nationale Glücksspielrecht und seine Folgen für Deutschland, Zeitschrift für Wett- und Glücksspielrecht, 8 (5), 305-313

Streinz, R. (Hrsg.) (2018), EUV/AEUV, 3. Auflage

Stulz-Herrnstadt, M. (2004), Nationale Rundfunkfinanzierung und europäische Beihilfenaufsicht im Lichte des Amsterdamer Rundfunkprotokolls

Sucker, F. (2018), Der Schutz und die Förderung kultureller Vielfalt im Welthandelsrecht

Ukrow, J. (2018), Rundfunkbeitrag, Rechtsprechungsstabilität und neue Herausforderungen für die Vielfaltssicherung. Abgerufen von https://emr-sb.de/wp-content/uploads/2018/07/EMR-AktuelesStichwort-BVerfG-RF-Beitrag-180718.pdf

Vesting, T. (1991), Indexierung der Rundfunkgebühr - Möglichkeiten, Chancen, Risiken, Deutsches Verwaltungsblatt 106, 857-859

von Danwitz, T. (205), Die Kultur in der Verfassungsordnung der Europäischen Union, Neue Juristische Wochenschrift 58 (9), 529-536

von Komorowski, A. (2015), Der allgemeine Daseinsvorsorgevorbehalt des Art. 106 Abs. 2 AEUV, Europarecht, 50 (3), 310-329

von der Groeben, H., Schwarze, J. \& Hatje, A. (Hrsg.) (2015), Europäisches Unionsrecht, 7. Auflage

Wagner, E. (2011), Abkehr von der geräteabhängigen Rundfunkgebühr

Wemmer, B. (1996), Die neuen Kulturklauseln des EG-Vertrages

Wendel, M. (2011), Permeabilität im europäischen Verfassungsrecht.

Wusterhausen, U. (2016), Die Wirkungen der Urteile des EuGH in der Zeit

ZDF (2018), Jahresabschluss 2016. Abgerufen von https://www.zdf.de/zdfunternehmen/jahrbuch-2017 -finanzen-jahresabschluss-102.html 